\title{
SENSING OF CONTACT TUBE WEAR IN GAS METAL ARC WELDING
}

M.A. Mornis

T.P. Quinn

T.A. Siewert

J.P.H. Steele

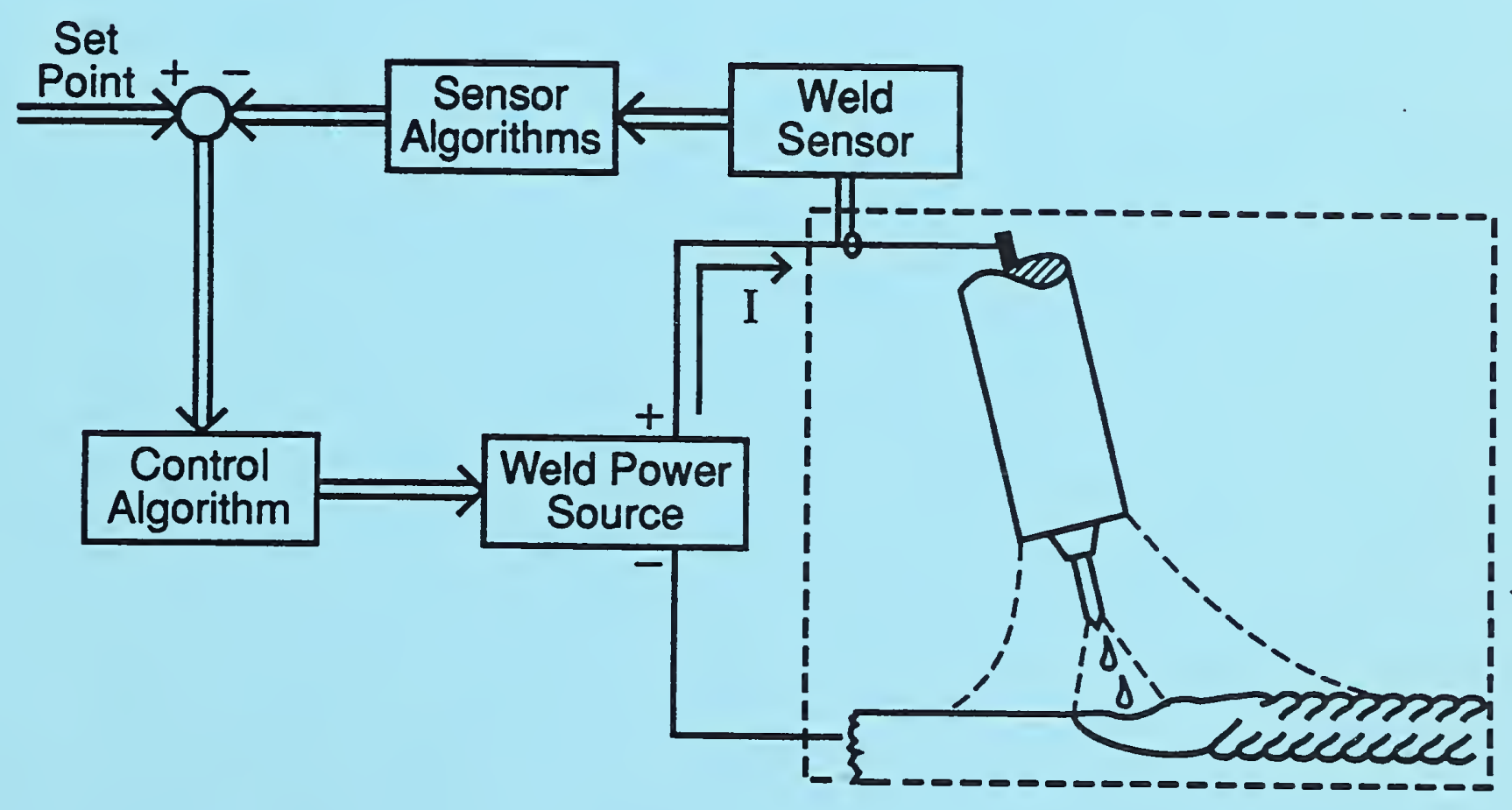





\section{SENSING OF CONTACT TUBE WEAR IN GAS METAL ARC WELDING}

M.A. Mornis

T.P. Quinn

T.A. Siewert

J.P.H. Steele*

Materials Reliability Division Materials Science and Engineering Laboratory National Institute of Standards and Technology Boulder, Colorado 80303

* Department of Mechanical Engineering Colorado School of Mines

Golden, Colorado 80401

September 1992

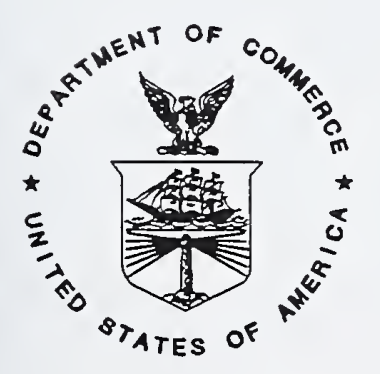

U.S. DEPARTMENT OF COMMERCE, Barbara Hackman Franklin, Secretary TECHNOLOGY ADMINISTRATION, Robert M. White, Under Secretary for Technology NATIONAL INSTITUTE OF STANDARDS AND TECHNOLOGY, John W. Lyons, Director 


\section{CONTENTS}

LIST OF FIGURES $\ldots \ldots \ldots \ldots \ldots \ldots \ldots \ldots \ldots \ldots \ldots \ldots$ iii

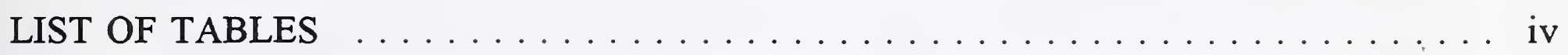

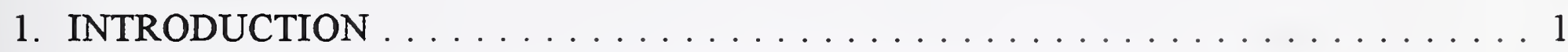

1.1 Gas Metal Arc Welding $\ldots \ldots \ldots \ldots \ldots \ldots \ldots \ldots$

1.2 Nomenclature . . . . . . . . . . . . . . . . . . . . 2

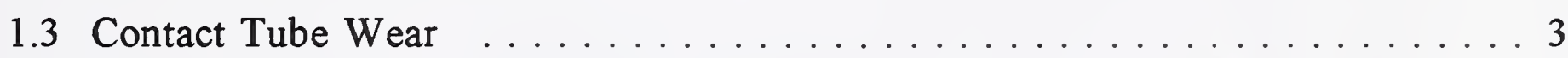

1.4 Contact Tube Failure . . . . . . . . . . . . . . . . . . . 3

1.5 Tube Wear With Constant Voltage Power Source . . . . . . . . . . . . 4

1.6 Tube Wear With Pulsed-Current Power Source . . . . . . . . . . . . . . 5

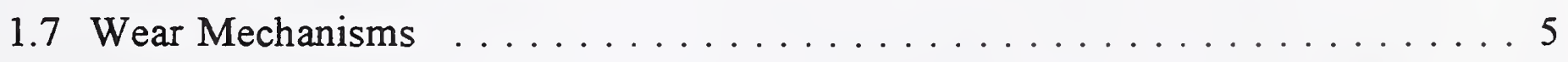

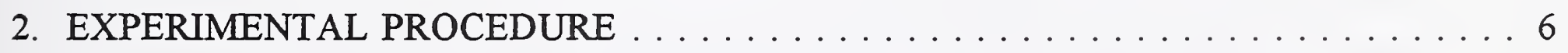

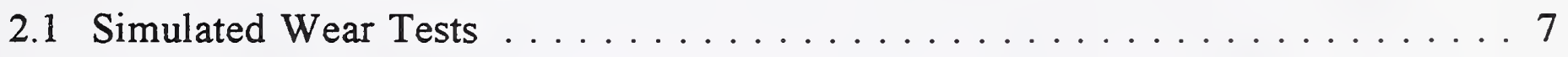

2.2 Actual Wear Tests . . . . . . . . . . . . . . . . . 8

2.3 Weave Test . . . . . . . . . . . . . . . . 9

3. RESULTS AND DISCUSSION . . . . . . . . . . . . . . . 9

3.1 Simulated Wear Tests (Drilled Contact Tubes) . . . . . . . . . . . . . 9

3.2 Actual Wear Tests . . . . . . . . . . . . . . . . . . . . 16

3.3 Weave Test ......................... 27

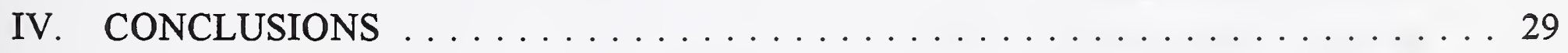

V. REFERENCES ............................ 30 


\section{LIST OF FIGURES}

Figure

$\underline{\text { Page }}$

1. Contact tube and electrode

2. Electrode positioning: work angle and travel angle

3. Weave test

4. Mean current versus bore size 10

5. SD of current versus bore size

6. PSD current - 0 to $100 \mathrm{~Hz}$ for varying bore diameter

7. PSD voltage - 0 to $50 \mathrm{~Hz}$ for varying bore diameter

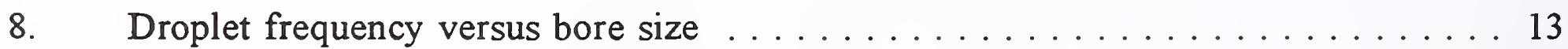

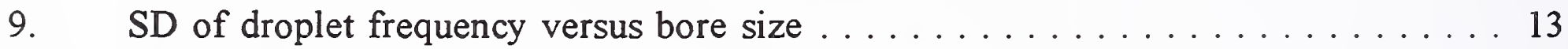

10. Droplet profile with enlarging bore size . . . . . . . . . . . . . . . . 14

11. Range of visible electrode length versus bore size . . . . . . . . . . . . 15

12. SD of droplet frequency versus ratio of bore/electrode diameters . . . . . . 15

13 Voltage signal with increasing weld time . . . . . . . . . . . . 17

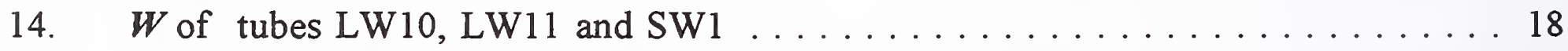

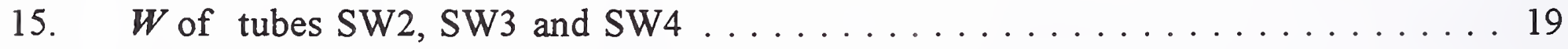

16. Wear pattern for GMAW process with steel electrode . . . . . . . . . 20

17. $W$ and $R$ versus length of electrode fed for tube $A 2 \ldots \ldots \ldots \ldots \ldots \ldots$

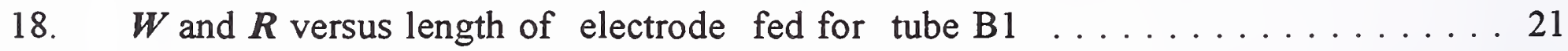

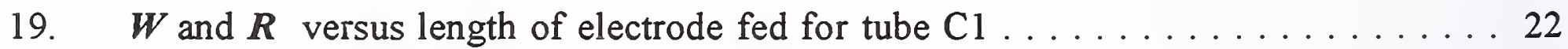

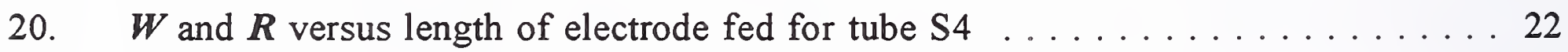

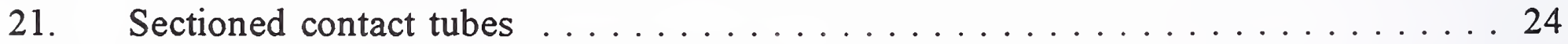

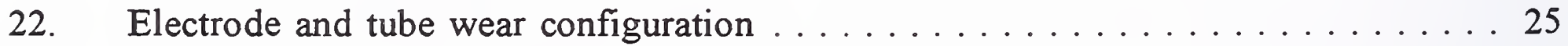

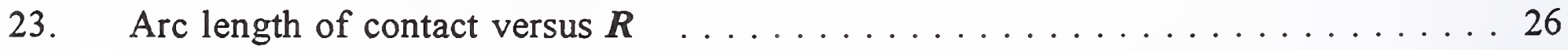

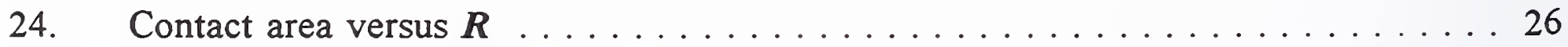

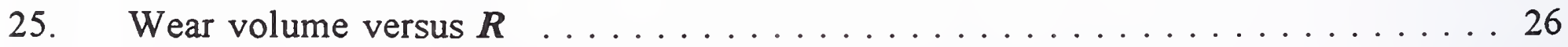

26. PSD voltage for sequential stringer and $1 \mathrm{~Hz}$ weave beads with a new contact

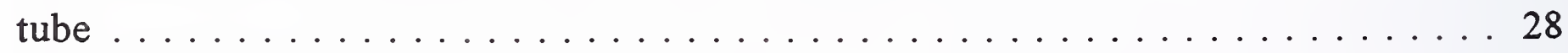

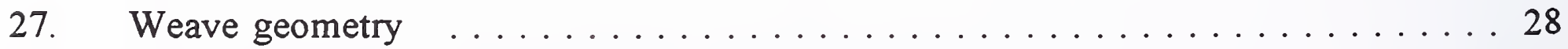

28. $W$ Versus length of electrode for stringer and weave tests . . . . . . . . . 29 


\section{LIST OF TABLES}

$\underline{\text { Table }}$

1. Actual wear tests - Group I . . . . . . . . . . . . . . 16

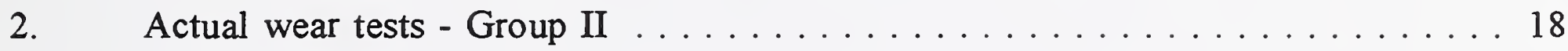

3. Actual wear tests - Group III . . . . . . . . . . . . . . . . . . . 19

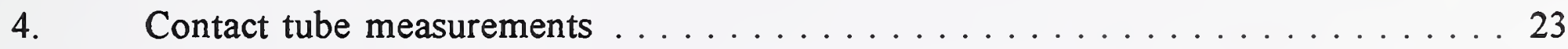




\section{ABSTRACT}

Welding tests confirm that the circuit voltage can serve as a through-the-arc sensing parameter for monitoring wear of the contact tube in gas metal arc welding. The integrated power spectral density curve $(\boldsymbol{W})$ of the voltage, within the 0 to $4 \mathrm{~Hz}$ range, correlated with wear. $W$ in this frequency range measured the arc stability, which degrades as the contact tube is eroded by the electrode. $W$ reached a peak value when the wear reached the maximum line contact between the electrode and the contact tube, then $W$ became erratic as the electrode started to oscillate within the slot that had worn in the tube.

\section{INTRODUCTION}

\subsection{Gas Metal Arc Welding}

In gas metal arc welding (GMAW), a continuously fed electrode melts as it enters an electric arc and molten droplets are transferred to the weld joint. The current passes from the contact tube to the electrode, through the arc, and then to the weld joint (Figure 1). Because of the series connection between these circuit elements, the static and dynamic characteristics of the arc are a combination of the response of these circuit elements. The following paragraphs list some of the important characteristics of these elements and how they affect the wear of the contact tube and the ability to sense the wear.

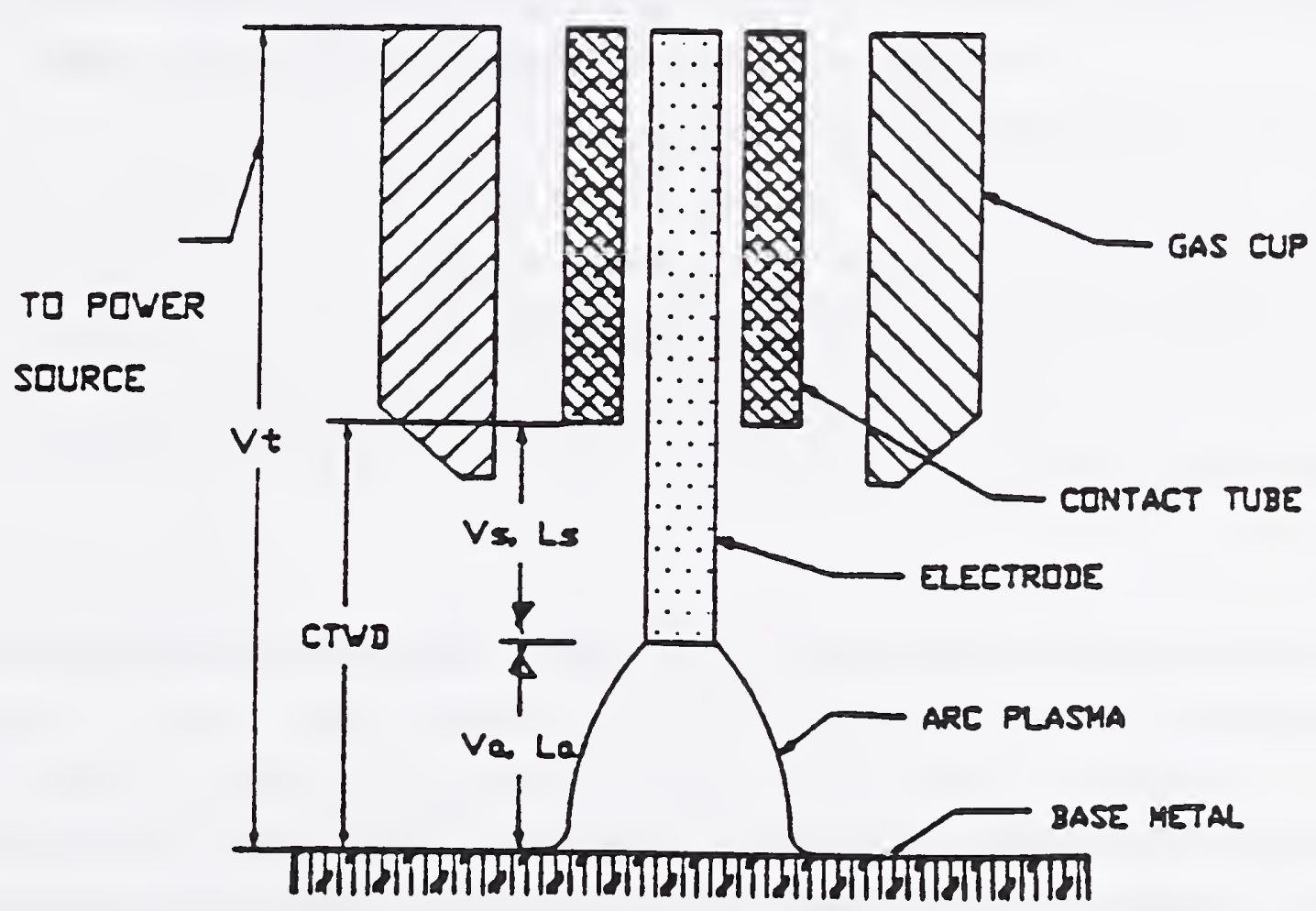

Figure 1. Contact tube and electrode. 
An externally supplied gas, generally a mixture based on $\mathrm{Ar}$ or $\mathrm{CO}_{2}$, is used to shield the molten weld metal from the atmosphere. Although a small amount of atmospheric contamination can be tolerated, most molten metals react with high levels of oxygen and nitrogen causing inclusions, porosity, or embrittlement. In addition to shielding the electrode and the base metal from contamination, the inert gases and any reactive gases form the plasma that stabilizes the arc.

The two most common types of power sources used in GMAW are constant voltage and pulsed current. A constant-voltage power source delivers a relatively fixed voltage during welding, with a slight decrease in voltage as more current is required (about $2 \mathrm{~V}$ drop for each $100 \mathrm{~A}$ ). An initial arc length, $L_{a}$, is determined by the combination of the arc voltage (set at the power source) and the electrode feed rate. A constant-voltage power source is inherently stable; any perturbation in the contact-tube-to-work distance, CTWD, changes the circuit impedance and is balanced by an instantaneous change in the current [1]. The magnitude of the current change is determined by the slope (drop in voltage as the current increases) of the characteristic curve of the power source. The power-source designer chooses a slope that increases the arc power when the arc is short and decreases the arc power when the arc is long, stabilizing the arc length.

In a pulsed-current power source, the arc current is switched between high- and lowcurrent intervals. The high-current interval serves to melt the electrode tip, pinch the molten column into droplets, and propel the droplets toward the base metal. The low-current interval serves to maintain the arc between the high-current pulses and preheats the electrode. A pulsed-current power source typically requires a feedback control system in the electrode feeder to compensate for changes in CTWD.

\subsection{Nomenclature}

Figure 1 also identifies the following parameters:

$\boldsymbol{L}_{s} \quad$ Electrode extension, the length of the electrode that projects beyond the contact tube to the arc.

$L_{a} \quad$ Arc length, the distance from the tip of the electrode (where melting occurs) to the weld pool.

CTWD Contact-tube-to-work distance, the distance from the contact tube to the base metal, also equal to the sum of the electrode extension, $\boldsymbol{L}_{s}$ and the arc length, $\boldsymbol{L}_{a}$.

$\mathbf{V}_{\mathbf{t}}$ Total voltage drop, from power source to base metal. 
$\mathbf{V}_{\mathbf{a}}$ Arc voltage, the voltage drop from the tip of the electrode to the base metal.

$V_{s} \quad$ Voltage drop from the point of current transfer to the tip of the electrode; in this figure the point of current transfer is assumed to be at the tip of the contact tube.

\subsection{Contact Tube Wear}

A contact tube is usually a copper alloy with a diameter (bore size) $0.2 \mathrm{~mm}$ to $0.5 \mathrm{~mm}$ larger than the welding electrode, depending on the tube hardness [2]. The tube aligns the electrode with respect to the welding gun and serves to transfer the welding current from the tube to the electrode. The electrode probably touches the contact tube in several places, so the current is shared between the contact tube and the electrode in a parallel circuit, yet most of the current travels through the contact tube until the final contact at the tip [3]. Less current travels through the electrode because (1) the electrode has a resistivity greater than that of the copper-alloy contact tube, (2) the electrode has been cold drawn raising its resistance further, and (3) the electrode has a smaller cross section. The point where the current transfers from the contact tube tip to the electrode is the location of any arc-related interaction between the electrode and the contact tube, such as an accentuation of wear in the presence of ohmic heating.

As the contact tube wears, the point of electrical contact probably moves between different points within the contact tube. As the point of contact changes, the current travels through different lengths of electrode to the arc (at least until the electrode can reestablish an equilibrium length). This varying electrode length leads to instability of the arc and determines the interval at which the contact tube must be replaced.

When a contact tube wears during manual GMAW, the welder compensates for changes in arc length by moving the welding gun toward or away from the base metal. The welder uses visual and audio feedback to identify a worn tube. As automation of GMAW progresses, a method of automatically monitoring the wear of the contact tube must be developed. An automatic system would either compensate for a worn tube or instruct the operator to replace the tube.

\subsection{Contact Tube Failure}

Failure of the contact tube can be defined as (1) catastrophic obstruction of the electrode or (2) generation of unacceptable instability in the welding process. Catastrophic obstruction terminates the weld and replacement of the tube is necessary before welding can continue. If a substantial amount of the contact-tube alloy has been melted and transferred to the weld pool, the weld may have to be rejected or grinding of the weld may be needed to remove this crack-prone material. Instability in the weld process occurs gradually, and the contact tube may be replaced between welds. If the instability is not noticed or corrected, the weld quality 
can deteriorate until the welds will not pass visual or NDE acceptance criteria. Weld quality may also be affected by increased wear of the contact tube because the electrode position may exceed position tolerances.

There are three types of catastrophic failure of contact tubes: (1) fusion of the electrode to the inside of the contact tube, (2) clogging of the tube due to weld spatter or other debris, and (3) melting the entire tip of the contact tube. If current consistently transfers to the electrode through a specific region of the tube, that region may overheat and the electrode may fuse to the inside of the tube at the point of current transfer. This fusion occurs when either the tube, the electrode, or both reach their melting temperature [2]. A contact tube tip can also melt if the arc length increases until it reaches the tip of the contact tube. Catastrophic failure also occurs when debris accumulates inside the tube, causing the electrode feed to hesitate and ultimately to stop. For titanium, DeNale and Lukens found that a copper-titanium intermetallic layer grew inside the contact tube until the electrode could not feed any more [2]. For most electrodes, the problem is the reverse; the contact tube wears. In these cases, any intermetallic compounds that might form apparently bond to the electrode and are carried out of the contact tube.

Failure of a contact tube can be defined as when the contact tube causes unacceptable instabilities in steady-state welding. The welding engineer must decide in each application when the instability starts to cause unacceptable weld quality, in characteristics such as weld profile, weld-bead alignment with the joint, penetration, or the risk of catastrophic failure.

\subsection{Tube Wear with a Constant-Voltage Power Source}

In a constant-voltage GMAW process, the power source voltage, $V_{t}$ is maintained nearly constant (changing only slightly in response to changes in the current). Under steadystate conditions, the current transfer point can be assumed to be at the tip of the contact tube, and the electrode extension, $\boldsymbol{L}_{s}$, can be assumed to remain constant during the weld. However, if $\boldsymbol{L}_{s}$ changes as the point of current transfer varies, the steady state assumptions are no longer valid. If $L_{s}$ increases, current decreases due to an instantaneous increase in electrode resistance. This results in an increase in voltage drop across the electrode and a decreased voltage drop across the arc, $V_{a}$. The decrease in $V_{a}$, arc length $\left(\boldsymbol{L}_{\boldsymbol{a}}\right)$, and welding current result in a decrease in power or heat input to the base metal. This reduction in heat should not severely change the welding conditions because, before long, the point of current transfer returns to the end of the contact tube and the electrode returns to its equilibrium length. However, instantaneous changes in the circuit resistance can be detected by changes in the circuit voltage and current. 


\subsection{Tube Wear with a Pulsed-Current Power Source}

A pulsed-current power source with voltage feedback control of the electrode feed speed reacts to wear of the contact tube in a different manner. The current is maintained at a set value by the power source. When $L_{a}$ changes due to wear, the voltage $\left(V_{t}\right)$ changes. In response, the feedback control system increases or decreases the electrode feed speed. If the electrode feed speed system is not critically damped, any overshoot in the feed speed creates oscillation in the arc length until the system stabilizes. When welding is performed at a high travel speed, the variations in arc length affect weld quality by changing the bead width.

\subsection{Wear Mechanisms}

Wear, in the case of sliding contact between two bodies, is the removal of surface material and transformation of the surface. Although several different wear mechanisms may be occurring simultaneously in a contact tube during GMAW, abrasion and adhesion seem to be the major contributors to the deterioration of a contact tube when welding with a steel electrode.

Abrasive wear is the removal of material by a hard asperity between the contact tube and the electrode, or the addition of a foreign body. Foreign bodies may be oxides embedded in the surface or wear particles formed during sliding. Resistance to abrasive wear is a function of hardness, and experiments have shown that abrasive wear occurs when the Vickers hardness (HV) of the asperity is 1.5 times greater than the abraded surface [4]. Even if the difference in hardness between the electrode and the contact tube were less, oxides and intermetallic compounds (formed by diffusion when heat is present) may meet this hardness criterion.

A steel electrode (ER 100S-1) with a tensile strength of 700 to $770 \mathrm{MPa}$ has a hardness of $205 \mathrm{HV}$ to $222 \mathrm{HV}$, while a copper alloy has a hardness of approximately $70 \mathrm{HV}[5,6]$. Although both these values underestimate the hardness of materials that have been cold worked, the hardness ratio for the two materials is still about 3 , so they meet the differential hardness criterion for abrasive wear.

Adhesion wear can be due to cold welding (formation of a metallurgical bond when materials are below their melting temperature) or hot welding (melting of one of the materials). Cold welding requires atomically clean surfaces for the bonding to occur. In the GMAW environment, the electrode surface is often oxidized, contaminated by debris, or coated with a lubricant to enhance feeding. In spite of these surface coatings, virgin surfaces can be exposed. These atomically clean surfaces are generated by asperities plowing through surface films of lubricants or oxides. Cold welding between these virgin surfaces of the electrode and the contact tube creates a bond which must be sheared by the electrode feeder or catastrophic feed failure occurs. If the cold weld between the electrode and the contact tube is strong (often the case with an intermetallic compound), the joint might shear within 
either the adjacent electrode or the contact tube metal. The failure of any cold welds for GMAW using a steel electrode and a copper alloy contact tube must occur within the contact tube because the diameter of the contact tube increases over time.

Gas metal arc welding with a titanium electrode and a copper-alloy contact tube provides an example of adhesion wear due to a hot weld. If the contact tube is heated to $1493 \mathrm{~K}$ by an arc within the tube, a localized pool of copper develops on the inside of the tube. Titanium dissolves in the molten copper, forming a low-melting-point eutectic that later solidifies as a hard intermetallic compound. This compound bonds strongly to the interior of the contact tube, resulting in an accumulation of hard intermetallic compounds inside the contact tube [2].

The removal of surface material can be quantified by wear volume, where wear volume (V) is proportional to the distance (l) or time of sliding, according to the formula

$$
\frac{V}{l}=\frac{K}{H},
$$

where $\mathrm{H}$ is the hardness of the softer material and $\mathrm{K}$ is some parameter specific to the wear conditions. This parameter may be a function of the normal load, the area of contact or the shape of the asperity [4].

\section{EXPERIMENTAL PROCEDURE}

The welding arc is affected not only by the shielding gas and power source, as described in the introduction, but also by electrode orientation and movement with respect to the base plate.

The electrode orientation can be defined by two angles, the travel angle (leading or trailing) and the work angle, as illustrated in Figure 2. In this study, the travel angle was adjusted for the most stable arc and this value was kept constant within each test matrix. The work angle was set as small as possible and was kept constant for each test matrix.

The travel speed was selected near the middle of the range used in production environments and was kept constant for each test matrix. The travel speed was relatively unimportant in this study because we were not concerned with the microstructure, the variable affected most by the heat input.

To investigate the various aspects of wear, several tests were used. These included simulated wear tests (which separated the effect of tube diameter from interior surface damage due to actual wear), three groups of wear tests, and an evaluation of the effect of electrode weave. The procedures were customized for each test group, as described in the following sections. 


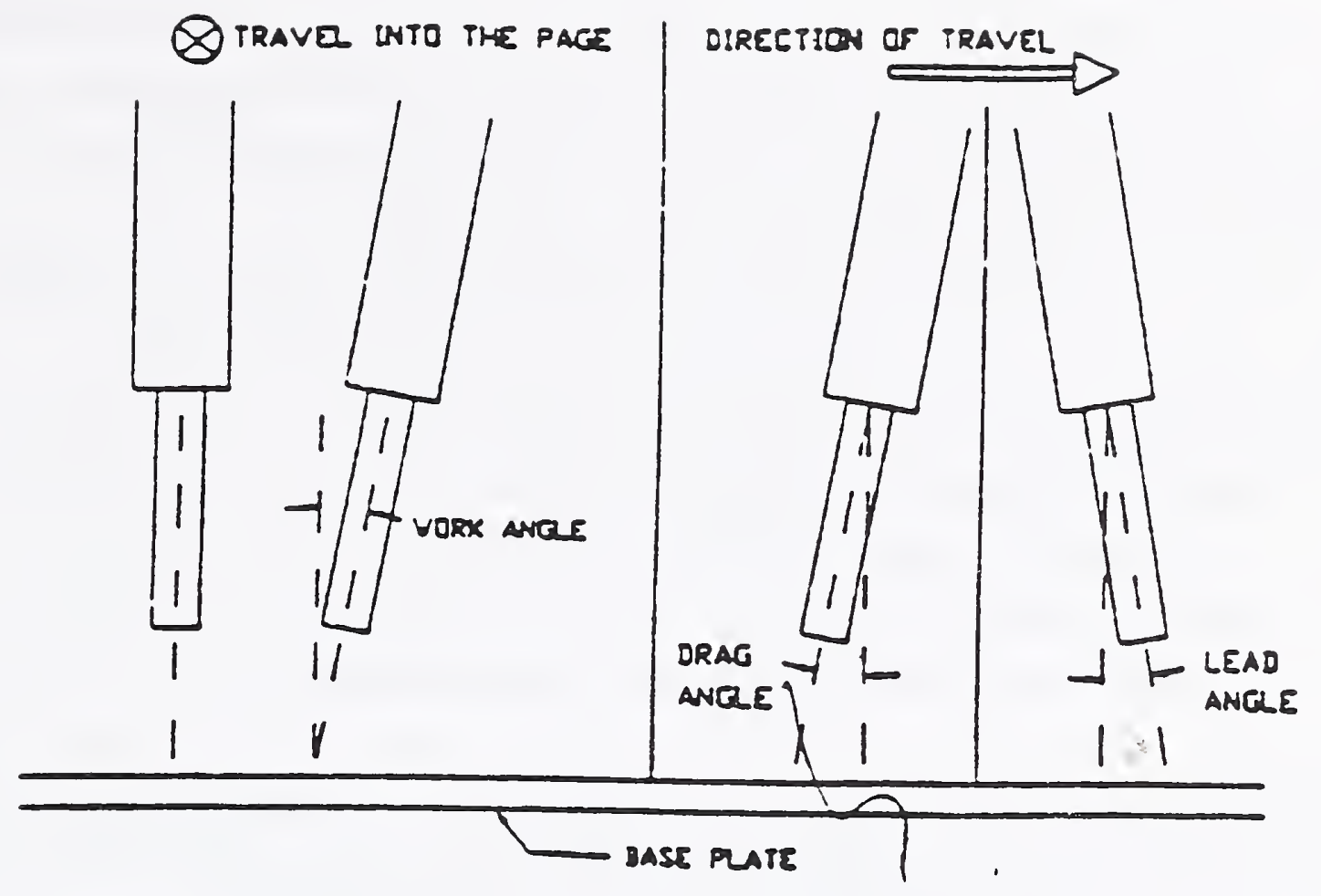

Figure 2. Electrode positioning: work angle and travel angle.

\subsection{Simulated Wear Tests}

A simple test was designed to simulate wear of a contact tube. New tubes were drilled to produce a range of internal diameters. The increasing diameters simulated the loss in electrode alignment that occurs when a tube is worn; however, the clean internal surface neglected the oxidation or other damage that occurs on the internal surface of the tube. The voltage and current were monitored and analyzed as welds were made with a constant-voltage power source and constant electrode feed rate. Droplet frequency, the rate of formation of drops of molten electrode which are propelled to the weld pool, was calculated from highspeed images of the weld [7].

The power source output of $32 \mathrm{~V}$ was filtered with a transistorized current regulator to reduce power-line ripple below $0.1 \mathrm{~V}$. The polarity was direct-current electrode positive (DCEP), in which the welding electrode is positive and the base metal is negative. The electrode was fed at $10 \mathrm{~m} / \mathrm{min}$, which produced a current of $300 \mathrm{~A}$. A stationary, watercooled, straight welding gun was positioned normal to the plate surface. The base metal was fastened to a motorized carriage under the stationary gun and moved with a velocity of 20 $\mathrm{cm} / \mathrm{min}$. The contact-tube-to-work distance (CTWD) was set at $13.5 \mathrm{~mm}$, and the shielding gas was a mixture of 95 percent $\mathrm{Ar}$ and 5 percent $\mathrm{CO}_{2}$. Through-the-arc imaging and the specific features of our imaging system have been described previously $[7,8]$. The magnification of the video system was 4.4, producing a resolution of $0.1 \mathrm{~mm} /$ pixel. 
Standard contact tubes with a bore diameter of $1.4 \mathrm{~mm}$ were drilled to diameters of $1.5 \mathrm{~mm}, 1.6 \mathrm{~mm}, 1.7 \mathrm{~mm}, 1.8 \mathrm{~mm}, 1.85 \mathrm{~mm}, 2.0 \mathrm{~mm}, 2.1 \mathrm{~mm}$, and $2.24 \mathrm{~mm}$. One contact tube with a bore diameter of $1.3 \mathrm{~mm}$ was used to represent an undersized bore. The electrode was an E70S-3 (low carbon steel) with a $1.14 \mathrm{~mm}$ diameter.

Three welds of $8 \mathrm{~s}$ duration were made with each contact tube, for a total of 30 welds. The welding voltage and current were acquired at a rate of 2000 samples/s.

The following data was calculated for each contact tube:

1. Mean and standard deviation of current,

2. Power spectral density (PSD) of current,

3. Droplet frequency, and

4. Length of electrode from the gas cup to the arc.

\subsection{Actual Wear Tests}

The actual wear tests were conducted in three groups. The combination of power source, contact tube, and other details are described in the following sections.

\subsubsection{Wear Test, Group I. Group I used a commercial pulsed-current power source with} voltage feedback control of the electrode feed speed. The polarity was DCEP. A curved water-cooled welding gun was used with a $0^{\circ}$ work angle, a $10^{\circ}$ trailing travel angle, and a long-life contact tube alloy (as described by the manufacturer). The base plate carriage was set at a travel speed of $14.7 \mathrm{~cm} / \mathrm{min}$, and the CTWD was $19 \mathrm{~mm}$. Shielding gas was a mixture of 95 percent $\mathrm{Ar}$ and 5 percent $\mathrm{CO}_{2}$ at a flow rate of $1.13 \mathrm{~m}^{3} / \mathrm{h}$. The average current setting ranged from $225 \mathrm{~A}$ to $250 \mathrm{~A}$.

The average dimensions of the carbon steel base metal plates were $25 \mathrm{~cm} \mathrm{x} 50 \mathrm{~cm} \mathrm{X}$ $2 \mathrm{~cm}$. After approximately $3 \mathrm{~min}$ of welding, the CTWD was checked and the gun was repositioned on a clean region of the base plate. Repositioning was necessary to maintain a consistent direction of travel and corresponding travel angle.

The current and electrode feed speed were measured at internal test points in the pulse power source. The internal electrode feed test point measures the input voltage to the electrode feed motor, and is generated by the internal feedback control system of the power supply. It is only approximately proportional to the actual electrode feed speed, but provided a convenient way to measure the feed stability. The voltage was measured across the two output terminals of the power source. The voltage, wire feed speed (WFS), and current were acquired at rates of 200,800 , and $2000 \mathrm{samples} / \mathrm{s}$. The signals were low-pass filtered (to eliminate aliasing) at $90 \mathrm{~Hz}, 360 \mathrm{~Hz}$ and $900 \mathrm{~Hz}$, respectively. The PSD of the voltage was calculated for analysis. 
2.2.2. Wear Test, Group II. Group II is similar to Group I except that standard life contact tubes were used. The mean current setting ranged from 150 to $220 \mathrm{~A}$ and the data acquisition rates for voltage, WFS, and current were 200, 220, and $2000 \mathrm{samples} / \mathrm{s}$. For the lower sampling rates the signal was first sent through $90 \mathrm{~Hz}$ and $100 \mathrm{~Hz}$ low-pass filters before computer acquisition. The PSD of the voltage and the area under the curve of the PSD of the voltage from 0 to $4 \mathrm{~Hz}, a$, were calculated from the acquired data.

2.2.3. Wear Test, Group III. Group III used the pulsed-current power source and a straight water-cooled welding gun with $0^{\circ}$ work and travel angles. Standard-life contact tubes (but from a different manufacturer) were used. Every 9 to $18 \mathrm{~min}$, the welding was stopped to confirm that the CTWD $(19 \mathrm{~mm})$ was correct and to measure the change in contact tube diameter with calipers. The shielding gas was 95 percent $\mathrm{Ar}$ and 5 percent $\mathrm{CO}_{2}$, the mean operating current was $300 \mathrm{~A}$, the data acquisition rates for the voltage and WFS were 200 samples/s, and the low pass filter was set at $90 \mathrm{~Hz}$. Two tube compositions were used: composition A was termed "standard life" by the manufacturer, and composition B was termed "extended life." The following information was calculated from the acquired data:

1. PSD of the voltage.

2. Area under the curve of the PSD of the voltage, $\boldsymbol{a}$.

3. Wear volume, contact surface, and arc length for the tube.

\subsection{Weave Test}

A weave of $1 \mathrm{~Hz}$ was used in a single wear test to determine its effect on the lowfrequency PSD data. Any changes in the CTWD due to the weave procedure are expected to appear within the 0 to $4 \mathrm{~Hz}$ frequency range of the power spectral density data. The test utilized the straight water-cooled weld gun at a $0^{\circ}$ work angle and a $10^{\circ}$ trailing travel angle, with the standard 1.4-mm-internal-diameter tube. The shielding gas mixture was 95 percent Ar and 5 percent $\mathrm{CO}_{2}$, the travel speed was set at $14.7 \mathrm{~cm} / \mathrm{min}$ and the acquisition rate was 220 samples/s. A 6-mm-thick steel bar was tack-welded to the base metal plate and tilted to approximately a $45^{\circ}$ angle to simulate a V-groove joint (Figure 3 ). The stroke on the horizontal oscillator was set to $10 \mathrm{~mm}$ and the CTWD was $19 \mathrm{~mm}$.

\section{RESULTS AND DISCUSSION}

\subsection{Simulated Wear Tests (Drilled Contact Tubes)}

3.1.1. Current Analysis. The mean and standard deviation of the welding current were calculated and plotted for the three weld tests conducted for each bore size. Figure 4 is the graph of mean current versus bore size (1.4 mm is standard bore), and Figure 5 is the graph of the standard deviation of current taken at each bore size. In previous experiments, Heald reported a small increase in the standard deviation of the weld current with an increase in 


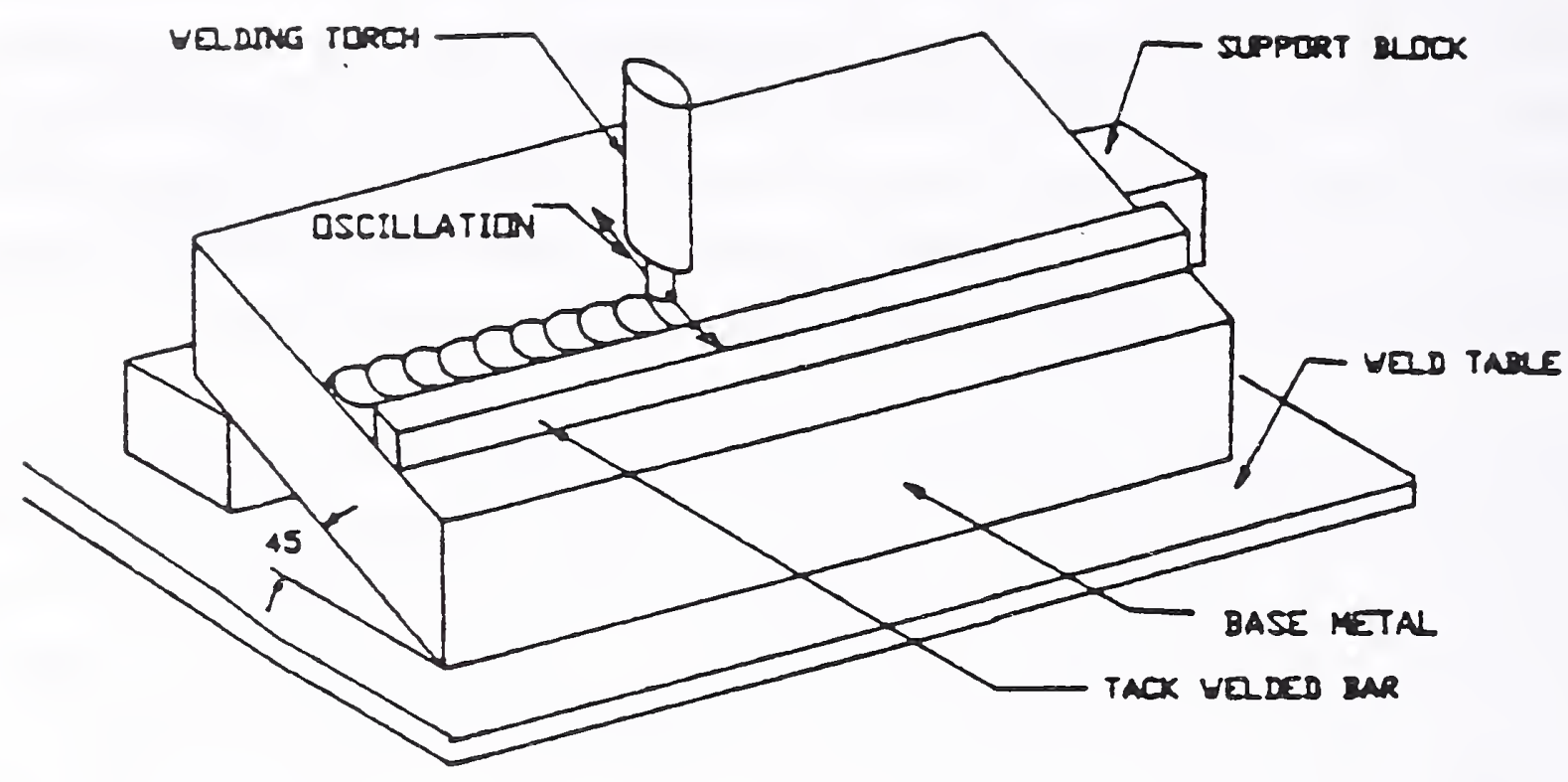

Figure 3. Weave test.

bore diameter [7]. However, the results of these tests do not show a correlation between standard deviation of current and bore size.

Another measure of arc stability is the magnitude of the PSD curve. We calculated $a$ using the fast Fourier transform [9]. Figure 6 shows the PSD current curves for frequencies

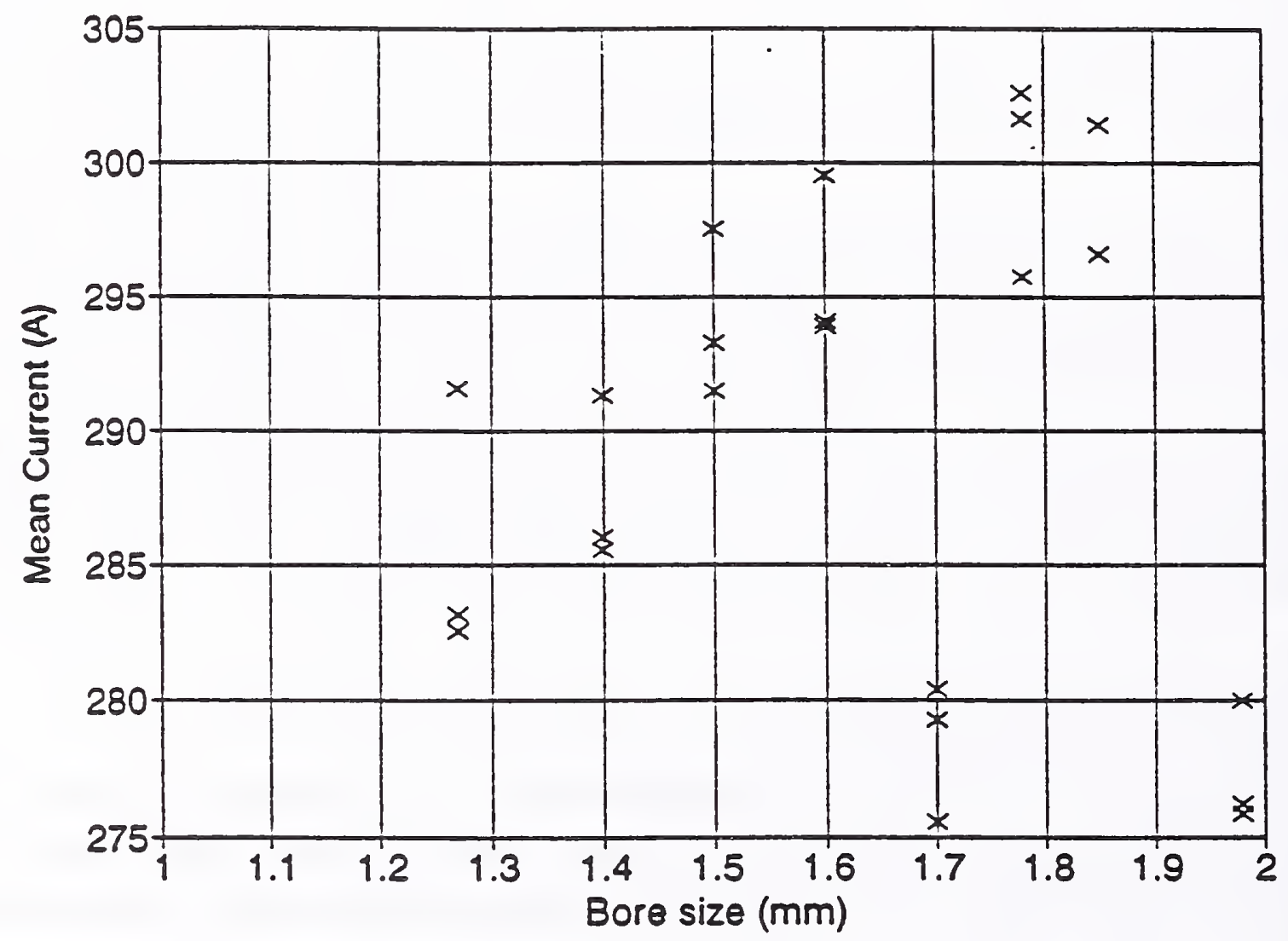

Figure 4. Mean current versus bore size. 


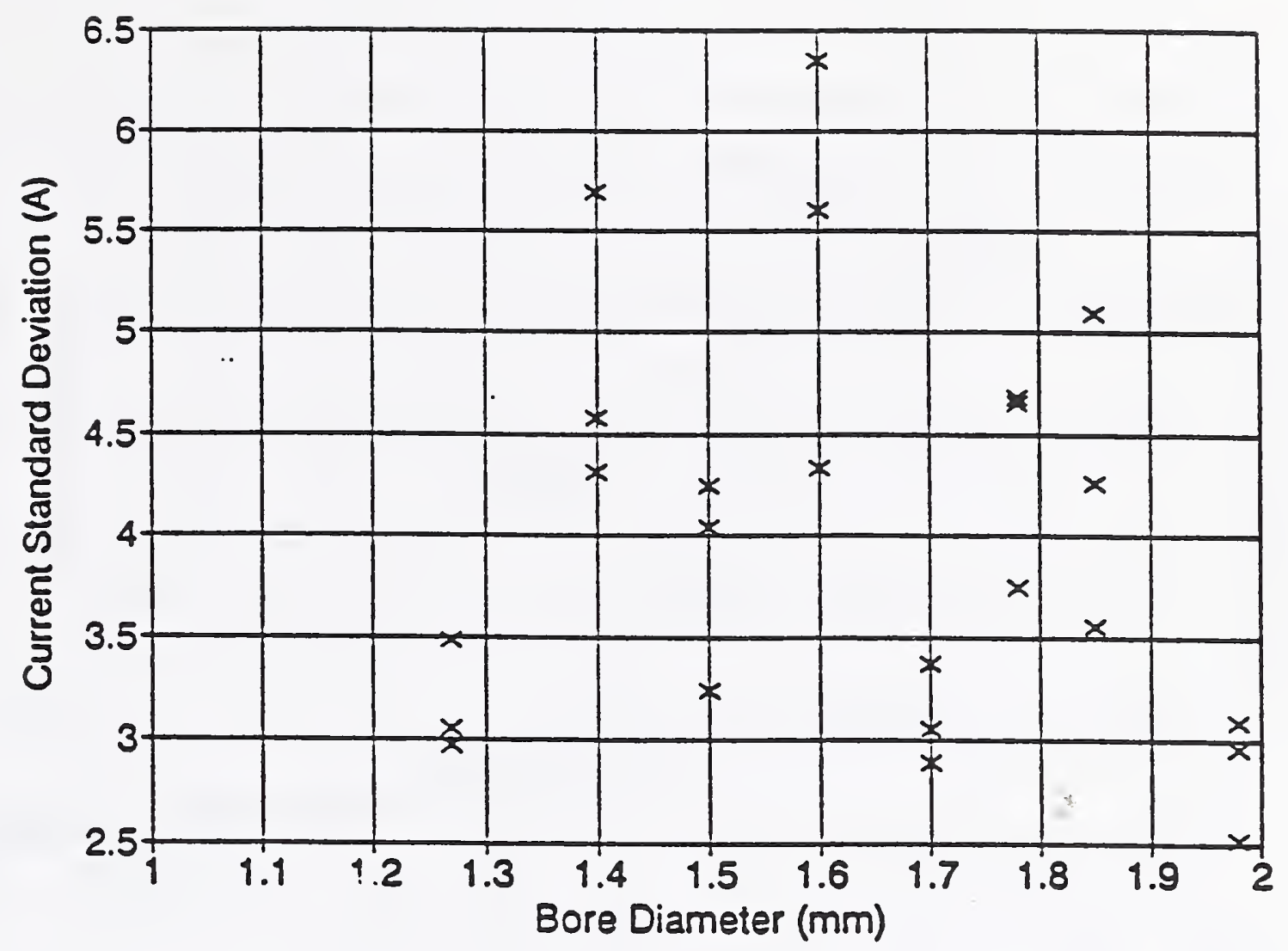

Figure 5. SD of current versus bore size.

from 0 to $100 \mathrm{~Hz}$, for varying bore diameters. This frequency range was selected for analysis because it contained the largest variations in the PSD magnitude as wear occurred. However, no consistent trend in current PSD magnitudes could be related to the bore diameters.

3.1.2. Voltage Analysis. The PSD of the arc voltage data is plotted in Figure 7. The lower frequency range of 0 to $50 \mathrm{~Hz}$ was selected for observation, and does not show a uniform increase with bore diameter.

3.1.3. Droplet Frequency Analysis. The droplet frequency was calculated by counting the number of frames which passed during the development of 10 drops of molten electrode. The duration of each frame was one-thousandth of a second. Figures 8 and 9 graph the droplet frequency and standard deviation versus bore diameter. The average droplet frequency increases with bore size with a low SD until the bore diameter of $1.85 \mathrm{~mm}$ is reached, at which point the average droplet frequency and SD peak. The high-speed images of the welding revealed that all contact tube diameters produced smaller secondary droplets along with a major droplet. The major droplets were counted to determine droplet frequency. The droplet form changed from small discrete droplets with short necking of the electrode, to elongated droplets generated from a long narrow neck. Between the bore diameters of 1.98 $\mathrm{mm}$ and $2.2 \mathrm{~mm}$, the mode of transfer changed from discreet droplets to a stream of molten 


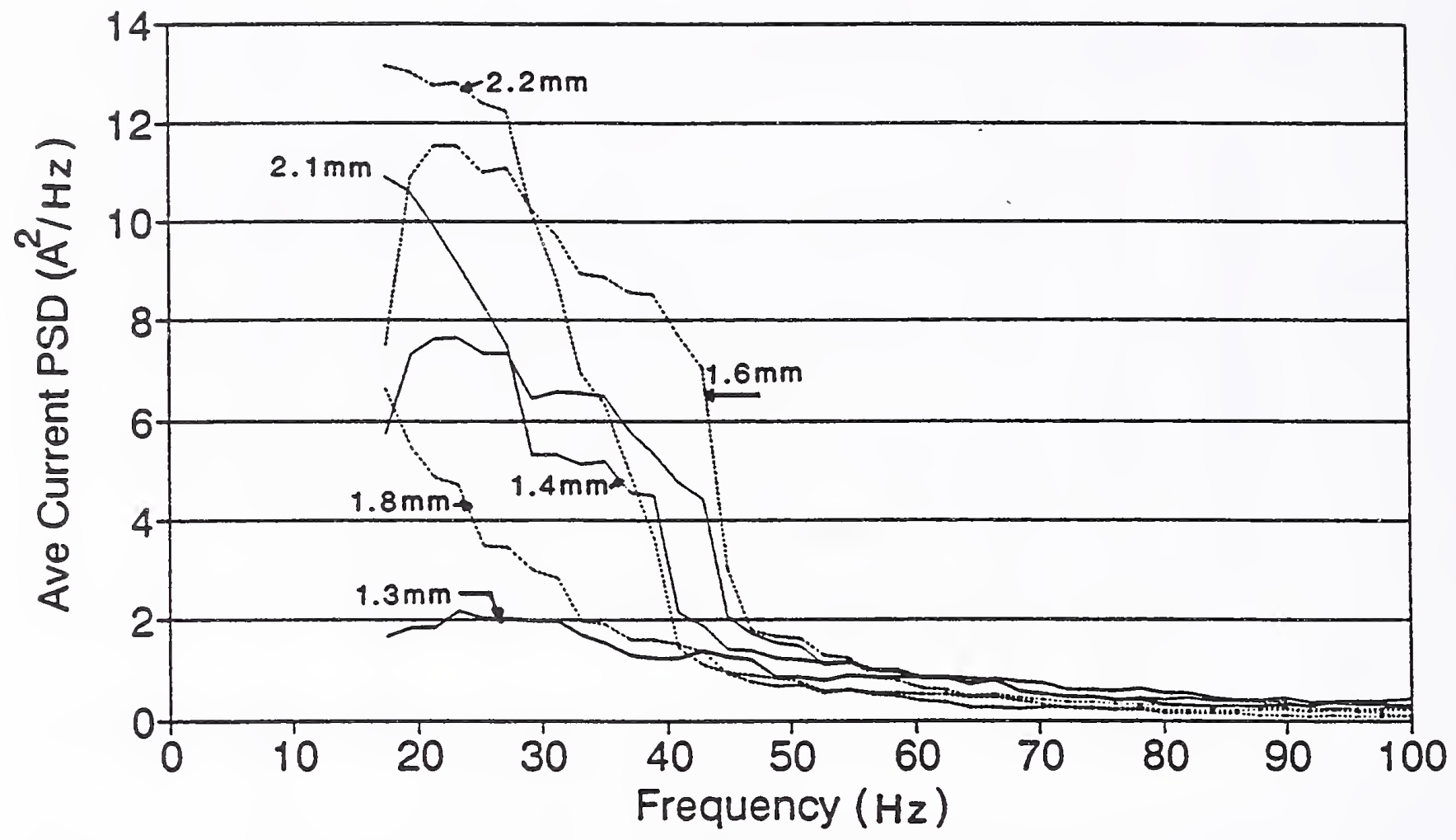

Figure 6. PSD current -0 to $100 \mathrm{~Hz}$ for varying bore diameter.

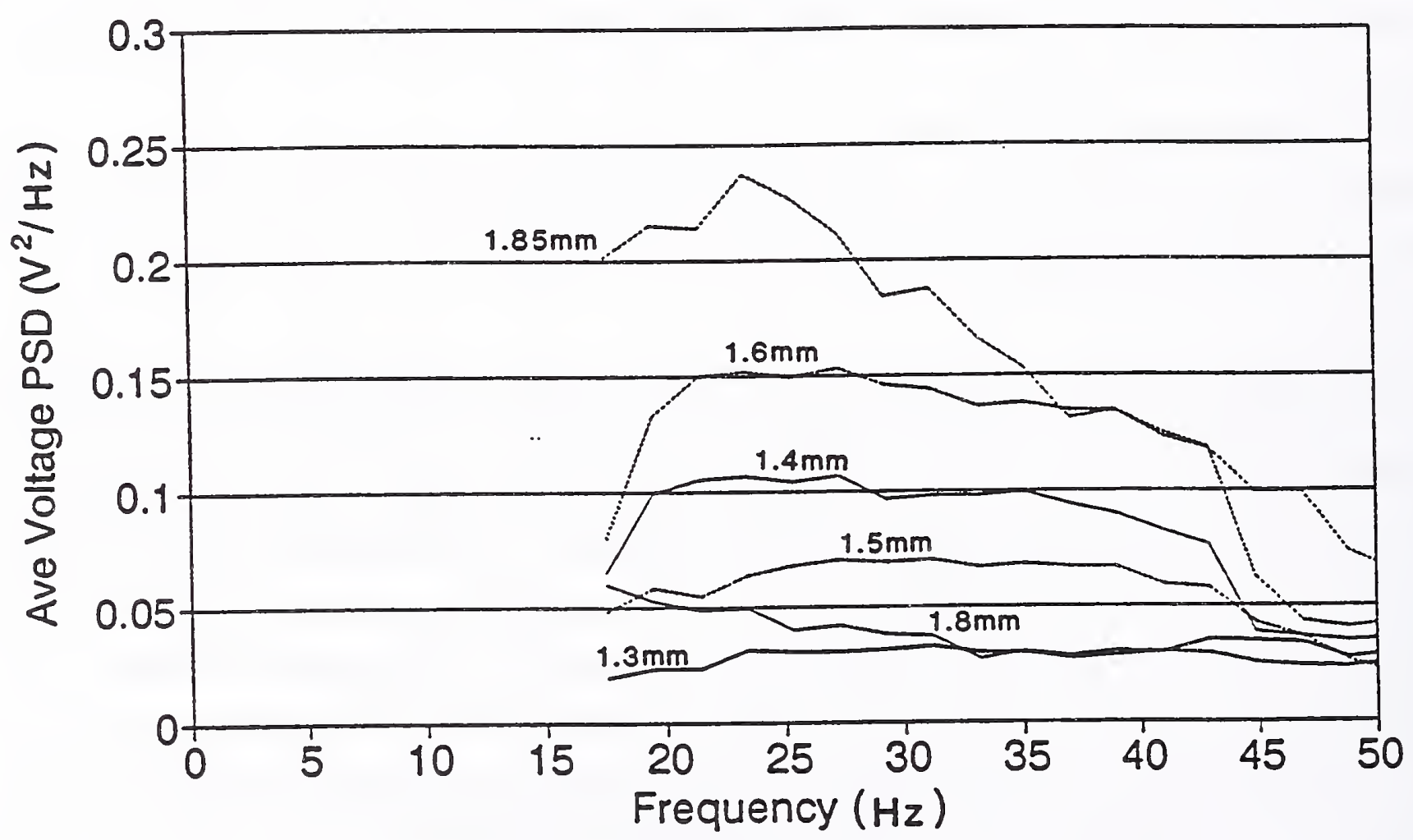

Figure 7. PSD voltage -0 to $50 \mathrm{~Hz}$ for varying bore diameter. 


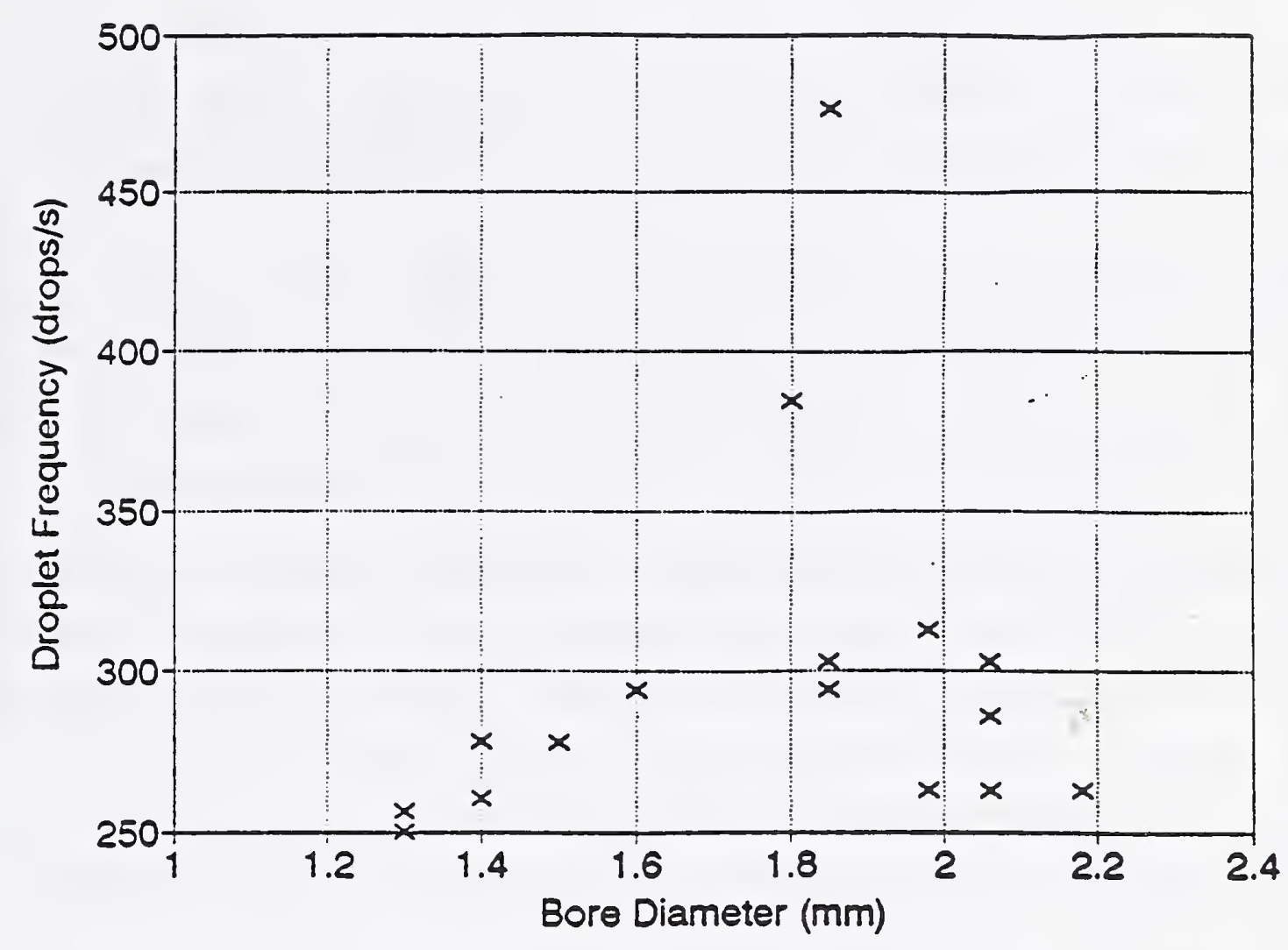

Figure 8. Droplet frequency versus bore size.

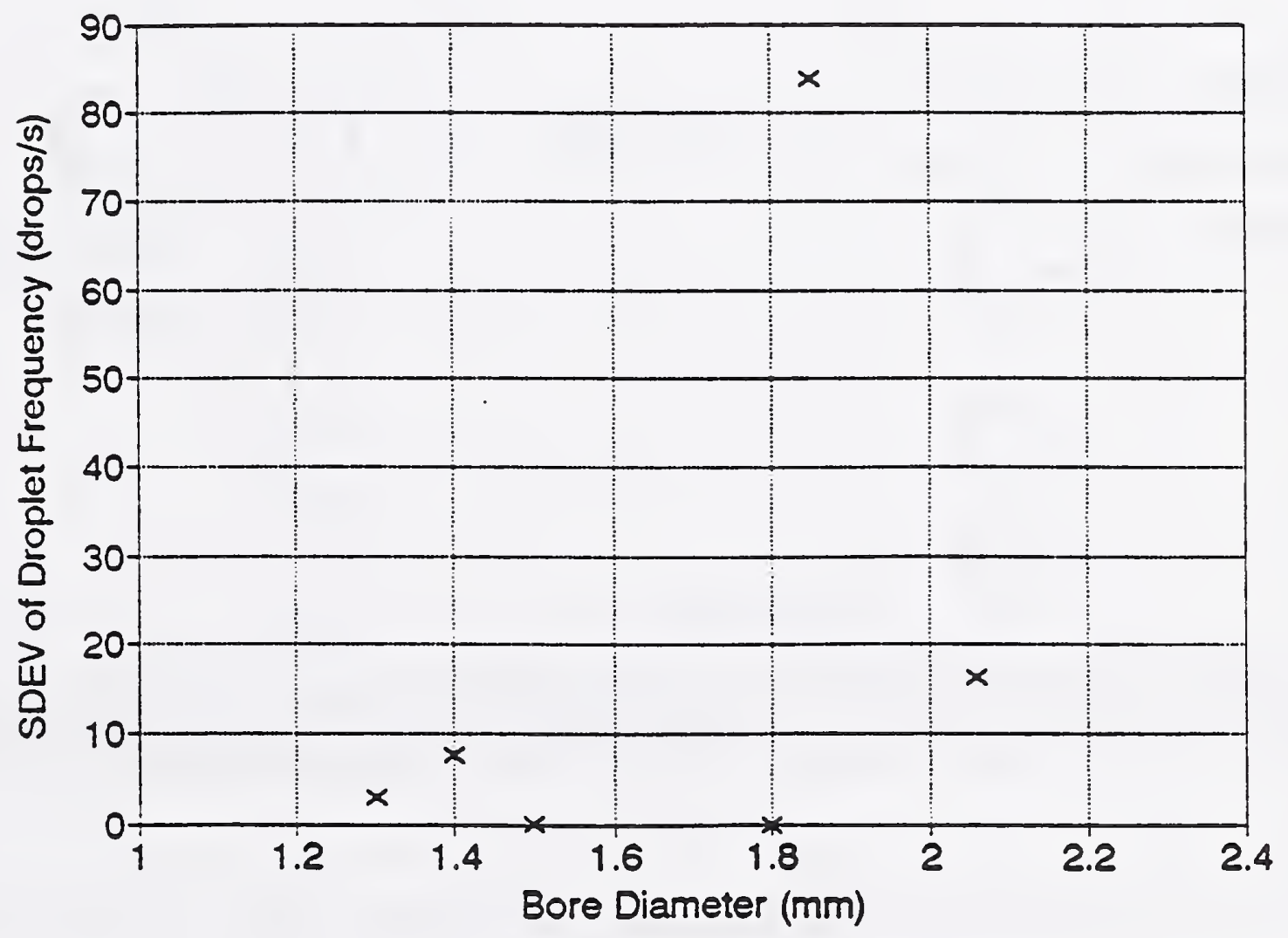

Figure 9. SD of droplet frequency versus bore size. 
electrode, Figure 10. Current affects droplet transfer mode, and the increase in average current with bore diameter may explain the change in droplet formation [7].

3.1.4. Arc Length Analysis. The extremes in arc length were calculated by measuring the visible electrode length for each tube on the video records. One effect of wear in a contact tube is an erratic arc length. Therefore, a greater spread in arc length was expected for an increase in bore diameter, but Figure 11 indicates no such correspondence.

\subsubsection{Discussion of Simulated Wear Tests. The standard deviation (SD) of droplet} frequency may be of use in selecting an optimum ratio of contact-tube diameter to electrode diameter for a constant-potential GMAW process. The low standard deviations of droplet frequency occur for a ratio of contact-tube-to-electrode ratio less than $1.62 \mathrm{~mm} / \mathrm{mm}$, as shown in Figure 12. The preferred droplet transfer mode occurs at a bore diameter less than 1.98 $\mathrm{mm}$ or a ratio of tube diameter to electrode diameter of less than $1.73 \mathrm{~mm} / \mathrm{mm}$.

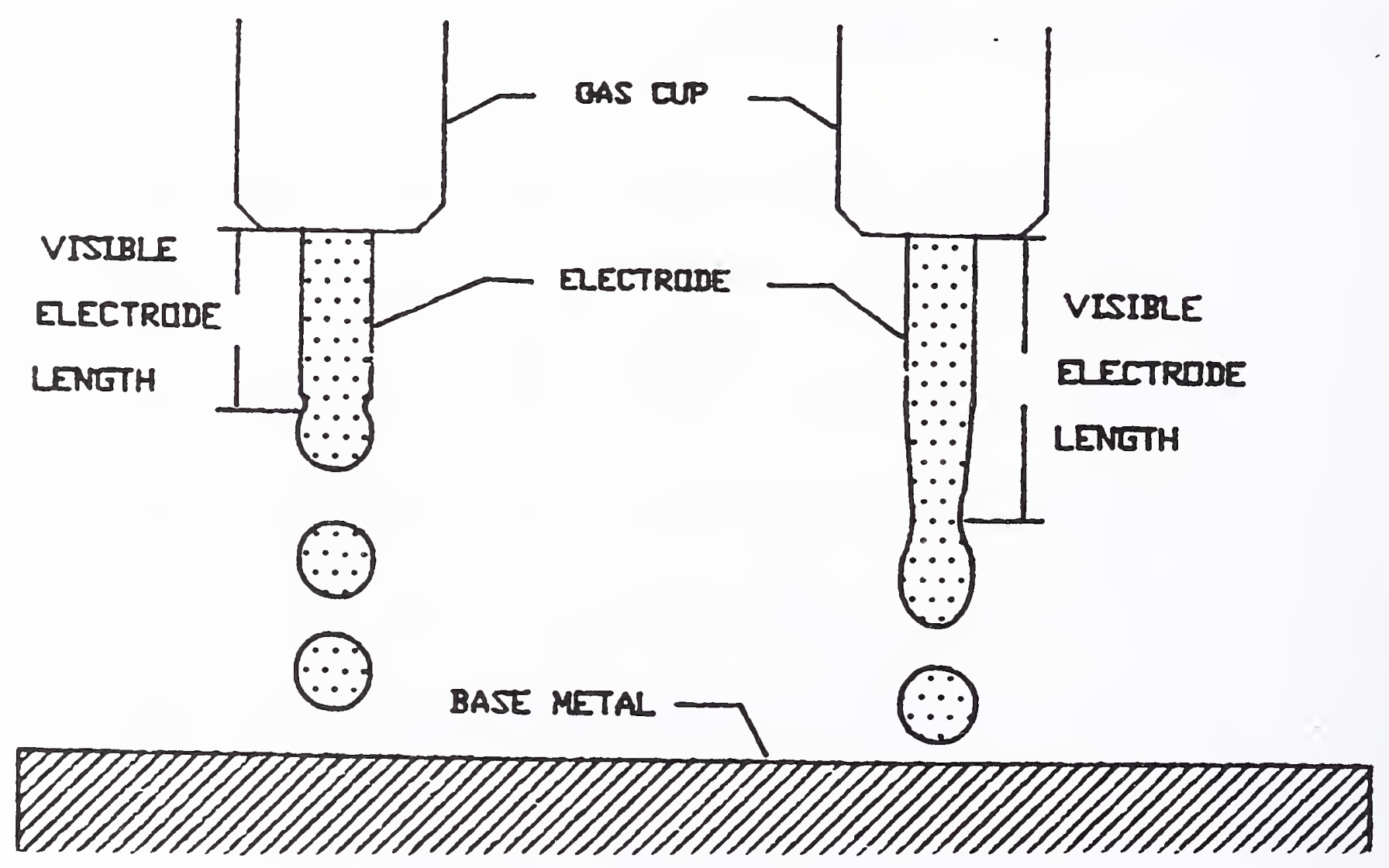

Figure 10. Change in droplet profile with enlarging bore size, with the larger bore on the right. 


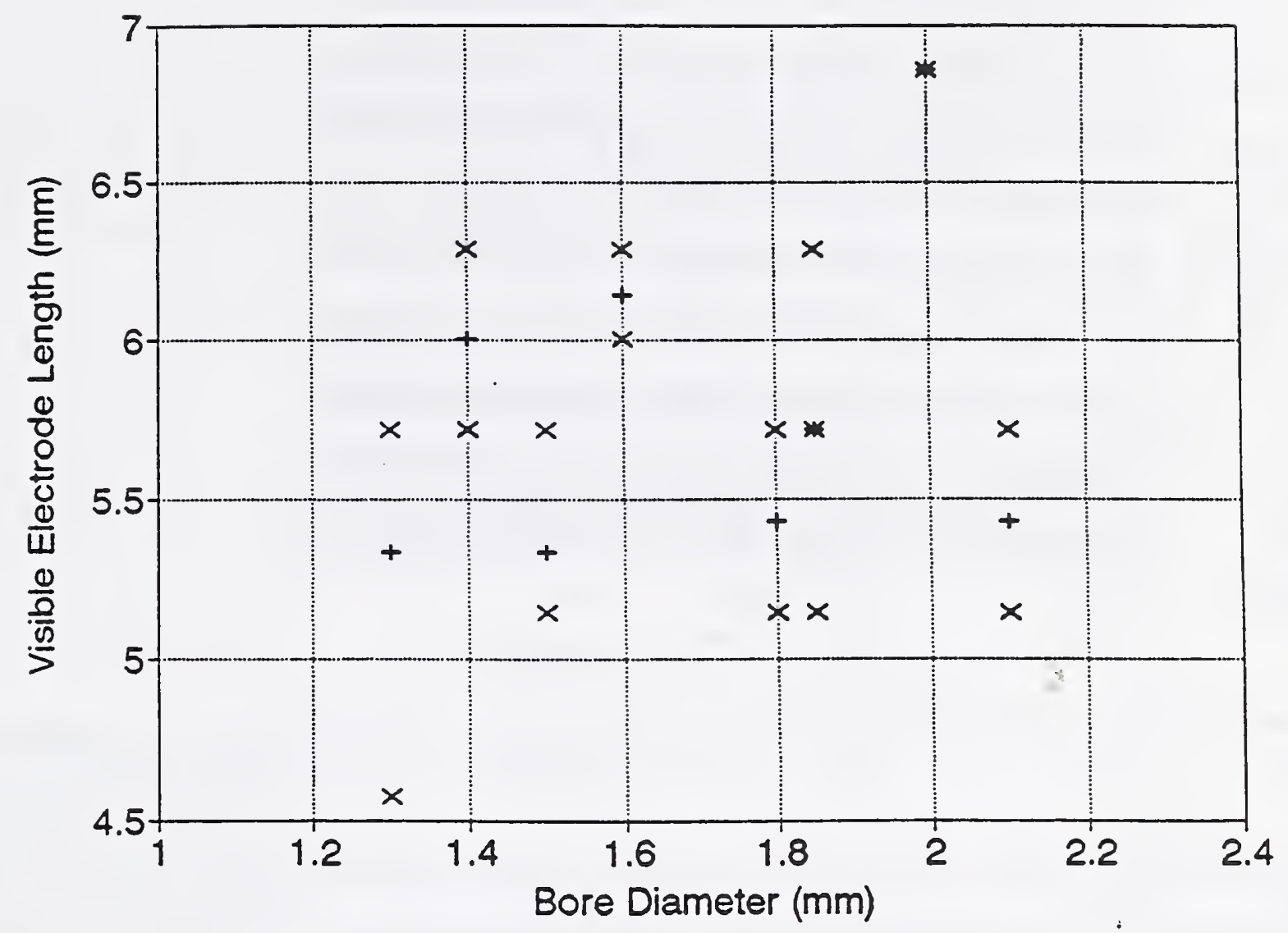

Figure 11. Range of visible electrode length versus bore size.

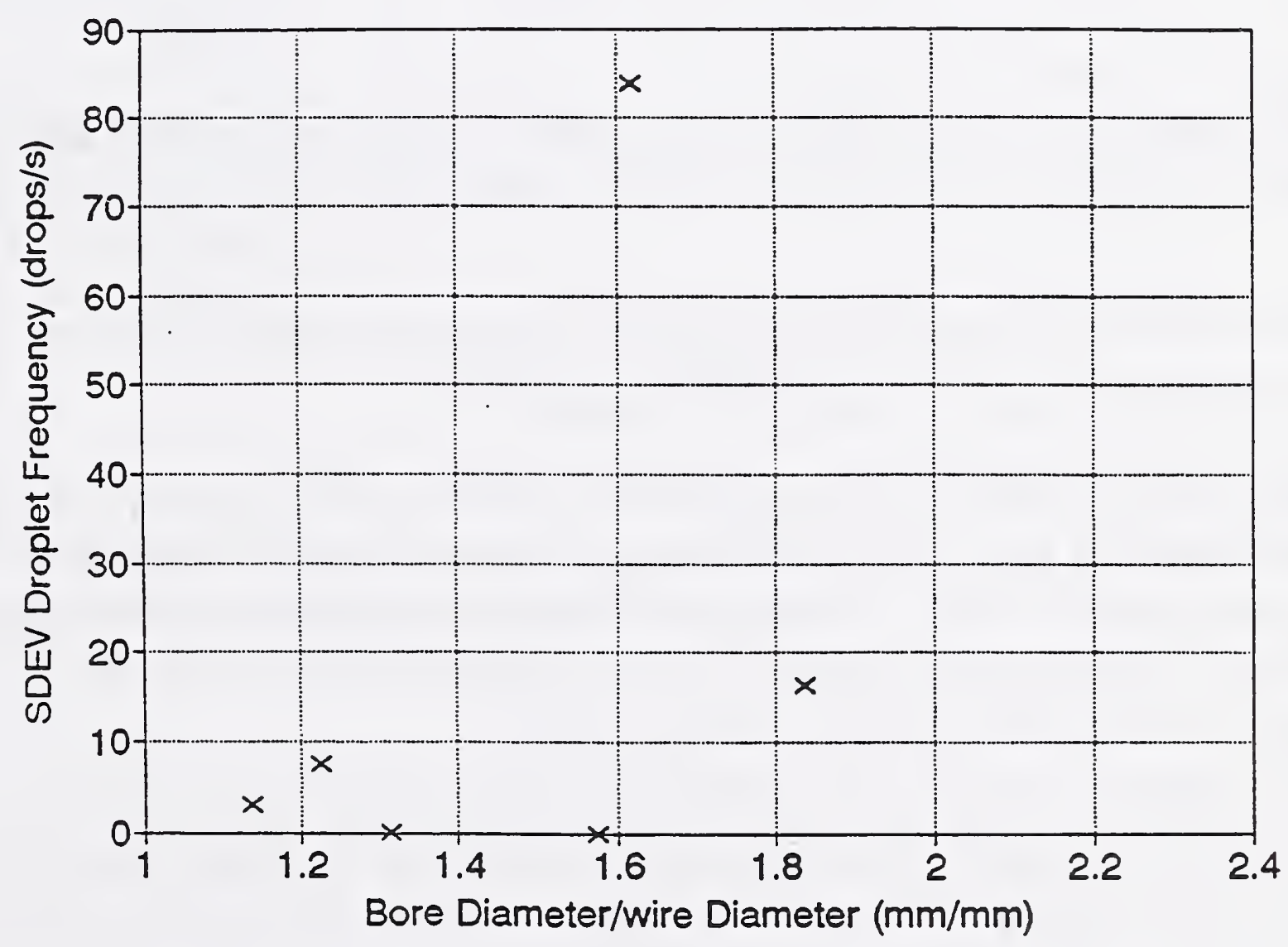

Figure 12. SD of droplet frequency versus ratio of bore/ electrode diameters. 


\subsection{Actual Wear Tests}

3.2.1 Wear Test Group I. Table 1 summarizes the results for the welds of Group I.

Electrode feed speed data (acquired at 2000 samples/s) were analyzed by counting the number of "outliers," defined as points where the WFS exceeded some multiple of the SD of electrode feed speed. The multiple was varied to find an increasing trend in the number of outliers with welding time.

Table 1 - Actual wear test - Group I.

\begin{tabular}{|c|c|c|c|c|}
\hline $\begin{array}{l}\text { Tube } \\
\text { number }\end{array}$ & $\begin{array}{l}\text { Welding } \\
\text { time } \\
\text { (min) }\end{array}$ & $\begin{array}{l}\text { Mean } \\
\text { amperage } \\
\text { (A) }\end{array}$ & $\begin{array}{l}\text { WFS sample } \\
\text { rate } \\
\text { (samples/s) }\end{array}$ & Comments \\
\hline LWO & 20 & 225 & 2000 & $\begin{array}{l}\text { E70S-3 electrode was } \\
\text { unstable, terminated test }\end{array}$ \\
\hline LW1 & 19 & 250 & 2000 & ER100S-1 electrode \\
\hline LW2 & 42 & 250 & 2000 & $\begin{array}{l}\text { Switched from } 250 \mathrm{~A} \text { to } \\
225 \mathrm{~A} \text { after } 28 \text { minutes }\end{array}$ \\
\hline LW4 & 135 & 250 & 2000 & $\begin{array}{l}\text { Electrode ran out at } 135 \\
\text { minutes }\end{array}$ \\
\hline LW 10 & 48 & 220 & 200,2000 & Electrode ran out \\
\hline LW11 & 62 & 220 & 200,2000 & $\begin{array}{l}\text { Leaky gas o-ring, moved } \\
\text { contact tube, stopped } \\
\text { welding }\end{array}$ \\
\hline
\end{tabular}

Note: Shielding Gas was 95 percent $\mathrm{Ar}-5$ percent $\mathrm{CO}_{2}$

This increasing trend in outliers appeared in the WFS data of contact tube LW4 with a limit of 3 times the SD. The outliers technique was not successful in providing a consistent rising trend relative to wear. Variations in electrode feed speed are a low-frequency phenomenon, therefore the acquisition rate was changed to include both 200 and 2000 samples/s for later tests in Group I.

The analysis of the PSD curve for the arc voltage showed an increased area under the curve in the 0 to $4 \mathrm{~Hz}$ frequency range for LW10 and LW11. Figure 13 shows the actual voltage recorded during welding with a single contact tube. The envelope of the voltage appears more ragged as wear progresses; this variation was also observed visually in the arc during testing. As wear advanced, the arc became more erratic. 


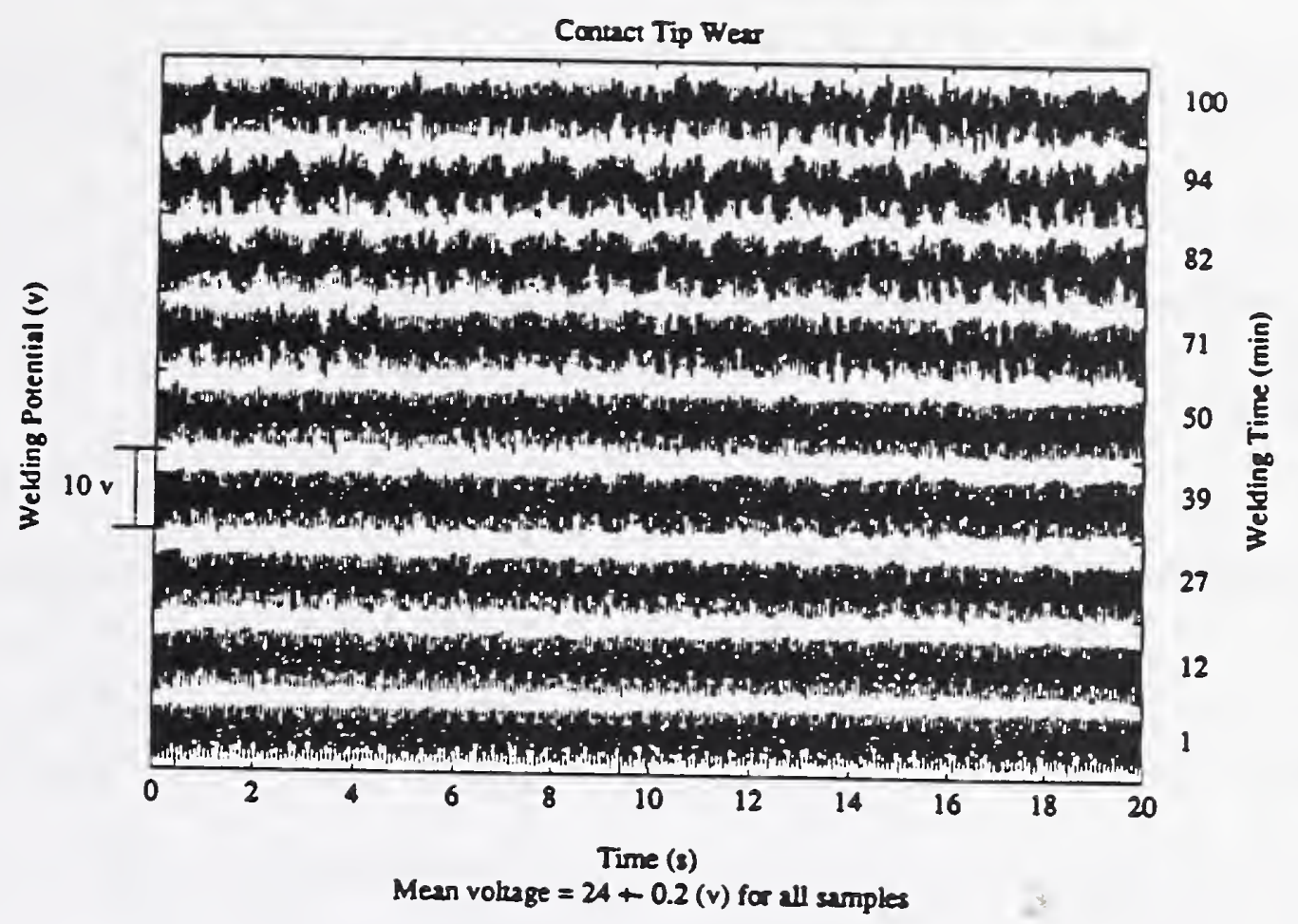

Figure 13. Voltage signal with increasing weld time.

The voltage (V) was sampled at time zero with a new contact tube at 200 cycles per $\mathrm{s}$ for a total of $90 \mathrm{~s}$, and every 10 to $15 \mathrm{~min}$ thereafter. The voltage data were normalized according to

$$
V^{\prime}=\frac{V-\bar{V}}{\bar{V}},
$$

where $\bar{V}$ is the mean voltage and $V^{\prime}$ is the normalized voltage. Since the majority of voltage variance occurred in the 0 to $4 \mathrm{~Hz}$ range, the PSD in this frequency range was integrated to give

$$
a=\int_{0}^{4 H z} P\left(V^{\prime}\right) d f,
$$

where $\mathrm{F}$ is frequency. To better indicate wear, a was normalized with a at $\mathrm{L}=0$ calculated when the contact tube is first placed in the welding gun:

$$
W(L)=\frac{a_{(L)}}{a_{(L=0)}},
$$

where $\mathrm{L}$ is the total length of the electrode consumed using the contact tube and $W$ is our wear parameter. 
3.2.2 Wear Test Group II. Table 2 summarizes the results for the Group II welds.

Table 2. Actual wear test - Group II.

\begin{tabular}{|l|l|l|l|l||}
\hline $\begin{array}{l}\text { Tube } \\
\text { number }\end{array}$ & $\begin{array}{l}\text { Welding } \\
\text { time } \\
\text { (min) }\end{array}$ & $\begin{array}{l}\text { Mean } \\
\text { current } \\
\text { (A) }\end{array}$ & $\begin{array}{l}\text { Sample } \\
\text { rate } \\
(\text { samples/s) }\end{array}$ & Comments \\
\hline \hline SW1 & 105 & 150 & 200,2000 & $\begin{array}{l}95 \% \mathrm{Ar}-5 \% \mathrm{O}_{2} \text { shielding } \\
\text { gas }\end{array}$ \\
\hline SW2 & 99 & 150 & 200 & $\begin{array}{l}\text { Tube moved, stopped at } 99 \\
\text { min }\end{array}$ \\
\hline SW3 & 102 & 150 & 200 & 200 \\
\hline SW4 & 140 & 220 & $\begin{array}{l}\text { SW4 used in weave test } \\
\text { and bore was measured }\end{array}$ \\
\hline
\end{tabular}

Note: Shielding gas for SW2, SW3, and SW4 was 95 percent $\mathrm{Ar}$ and 5 percent $\mathrm{CO}_{2}$.

Figures 14 and 15 show $W$ of arc voltage versus length of electrode consumed for contact tubes with different compositions and designs, different weld gases, and different average currents. $W$ steadily increased, reaching a peak $\left(W_{\mathrm{p}}\right)$ in all cases. After $W_{\mathrm{p}}$ was attained, the wear parameter became erratic, leveling off or decreasing in value. $W_{\mathrm{p}}$ can be identified in each case.

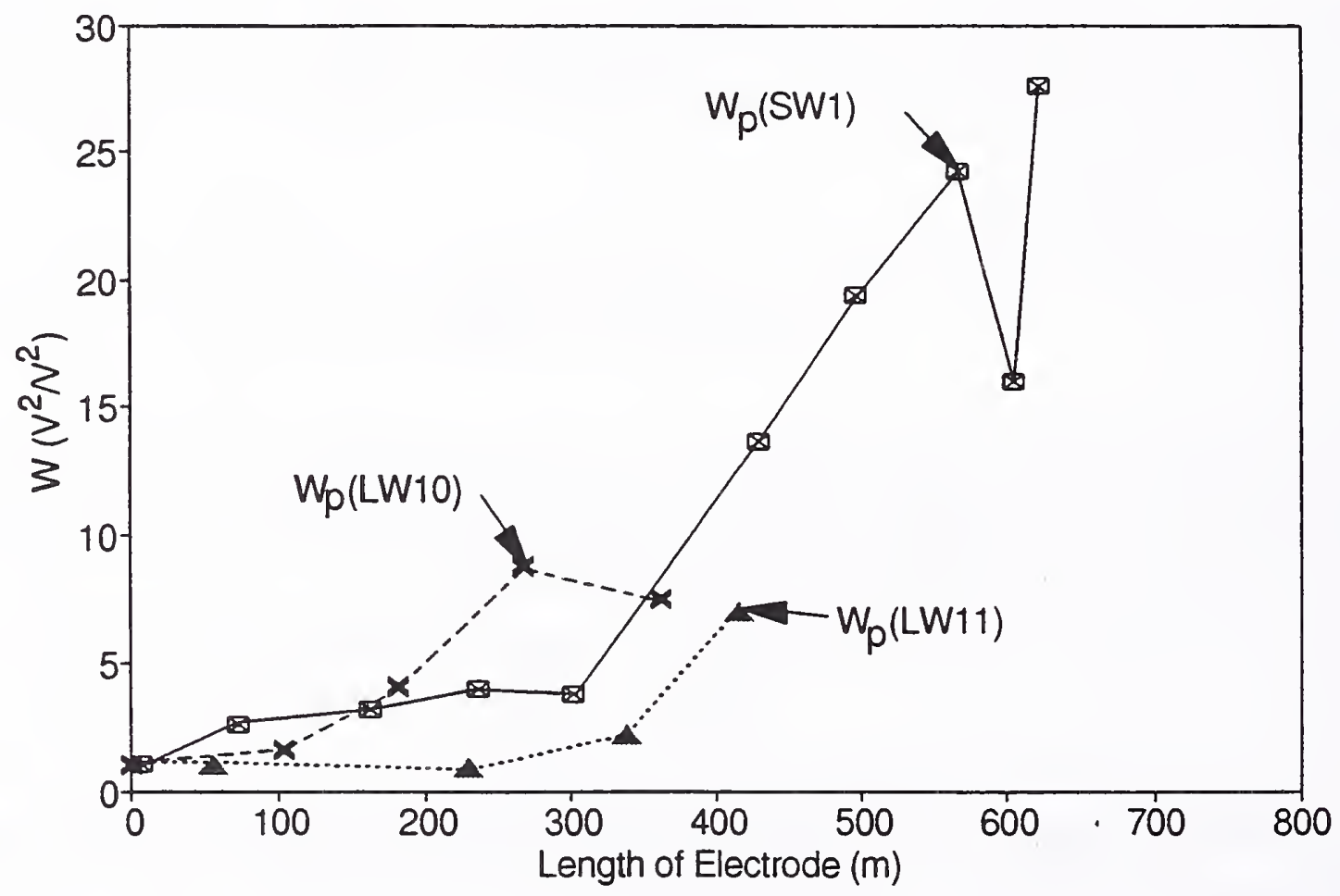

Figure 14. W of tubes LW10, LW11, and SW1. 


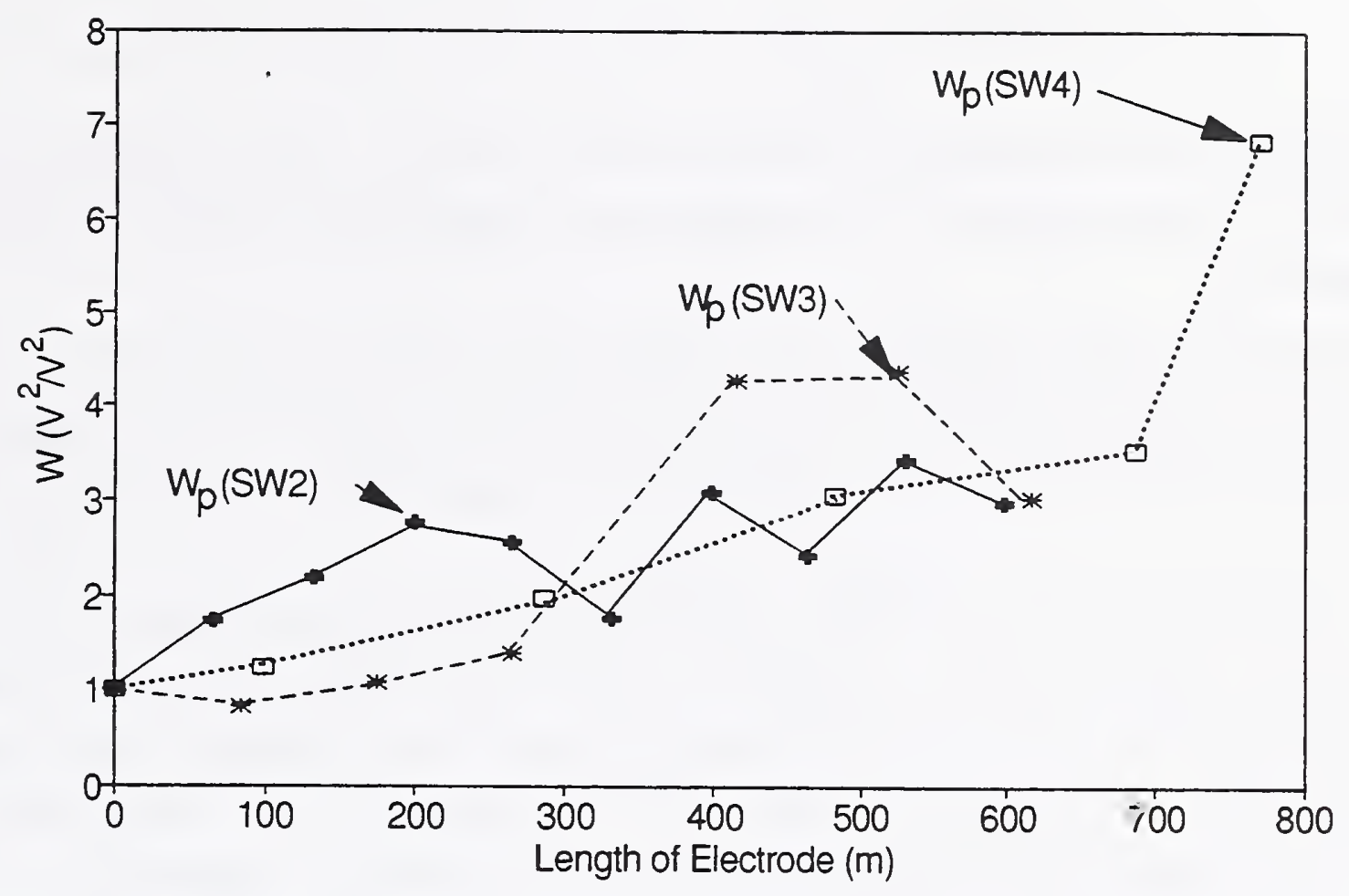

Figure 15. W of tubes SW2, SW3, and SW4.

3.2.3 Wear Test Group III. Group III used the same pulsed-current power supply as Group I and II, but a straight gun (instead of a curved neck) and contact tubes of different alloys were used, see Table 3. The current was increased to $300 \mathrm{~A}$, in order to operate at the recommended upper limit for the welding conditions.

Table 3. Actual wear test - Group III.

\begin{tabular}{||l|l|l|l|l||}
\hline $\begin{array}{l}\text { Tube } \\
\text { number }\end{array}$ & $\begin{array}{l}\text { Welding } \\
\text { time } \\
\text { (min) }\end{array}$ & $\begin{array}{l}\text { Mean } \\
\text { amperage } \\
\text { (amperes) }\end{array}$ & $\begin{array}{l}\text { Sample } \\
\text { rate } \\
\text { (samples/sec) }\end{array}$ & Comments \\
\hline \hline A1 & 252 & 300 & 200 & $\begin{array}{l}\text { Standard life tube alloy, } \\
1.4 \mathrm{~mm}(0.054 \text { in })\end{array}$ \\
\hline A2 & 90 & 300 & 200 & same tube as A1 \\
\hline B1 & 418 & 300 & 200 & $\begin{array}{l}\text { Extended life tube alloy, } \\
1.4 \text { mm }(0.054 \text { in })\end{array}$ \\
\hline C1 & 90 & 300 & 200 & $\begin{array}{l}\text { Standard life tube alloy, } \\
1.4 \mathrm{~mm}-1.6 \mathrm{~mm}(0.054 \text { in } \\
-0.062 \text { in })\end{array}$ \\
\hline
\end{tabular}

Note: Shielding gas 95 percent $\mathrm{Ar}$ and 5 percent $\mathrm{CO}_{2}$. Diameters of worn bores were measured for $\mathrm{A} 2, \mathrm{Bl}$, and $\mathrm{Cl}$ tubes. 
In Group III, the $W$ and companion bore were measured. The initial bore diameter at time zero $\left(D_{o}\right)$ and the length of the elongated bore developed in the direction of the cast $\left(D_{m}\right)$ were measured.

Cast is the curvature inherent in the electrode from electrode drawing and winding onto the spool. All wound electrode has a cast and whether a straight or curved gun is used, wear develops in the direction of the cast. Figure 16 is a typical wear pattern for the GMAW process.

The dimensionless wear ratio $(\mathbf{R})$ is created by dividing the enlarging diameter $\left(\mathrm{D}_{\mathrm{m}}\right)$ by the original bore diameter $\left(D_{\circ}\right)$. Figures $17,18,19$, and 20 show changes in $W$ and $\mathbf{R}$ with the increasing length of electrode fed through the tube during welding, for Group III and S4. $W_{\mathrm{p}}$ is identified in each graph. The wear ratio which occurs at the same time $W_{\mathrm{p}}$ is reached is labeled $\mathbf{R}_{\mathrm{p}}$. The wear ratio $\mathbf{R}_{\mathrm{p}}$ is not the peak wear ratio; it is the wear ratio which corresponds to the point at which the largest area under the power spectral density curve is reached $\left(W_{\mathrm{p}}\right)$. For the straight welding gun, $\mathbf{R}_{\mathrm{p}}$ falls within a range from 1.44 to 1.55 .
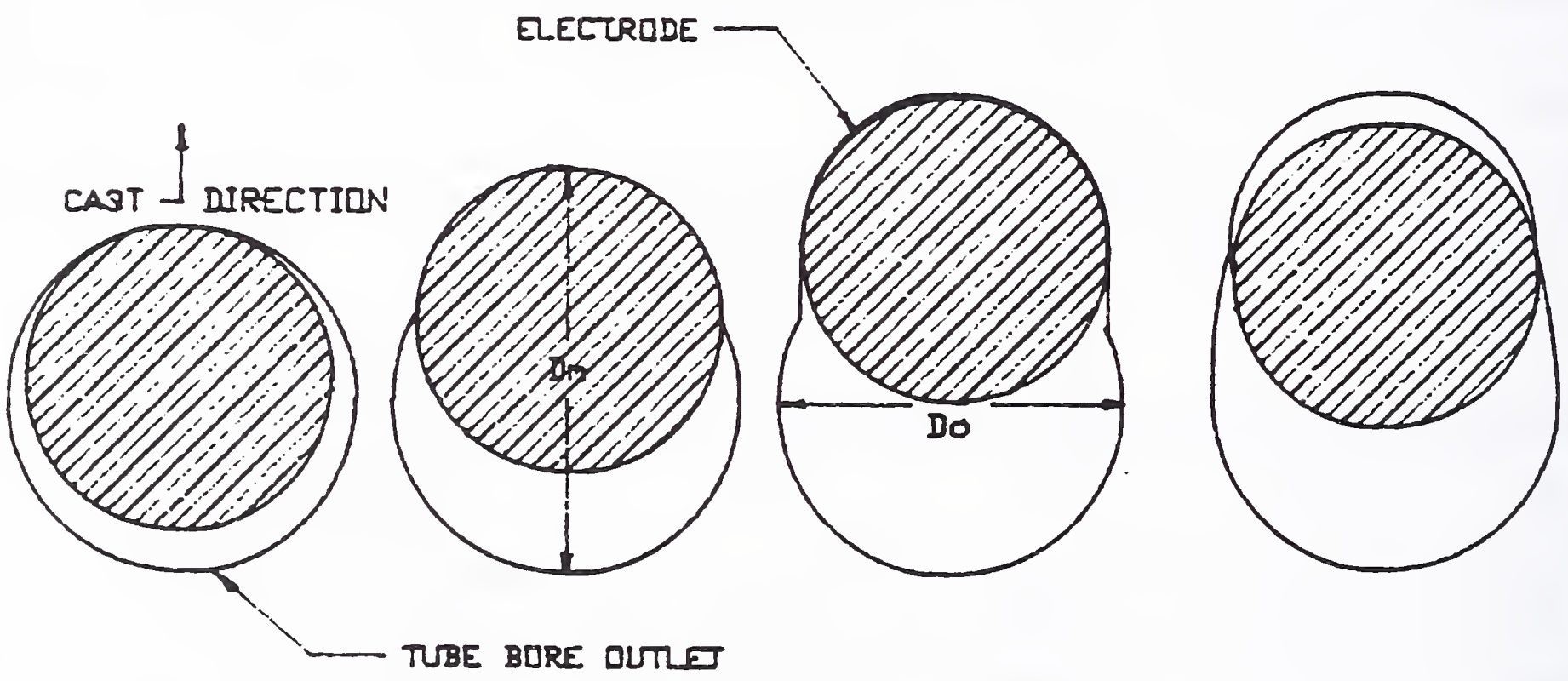

Figure 16. Wear pattern for GMAW process with steel electrode. 


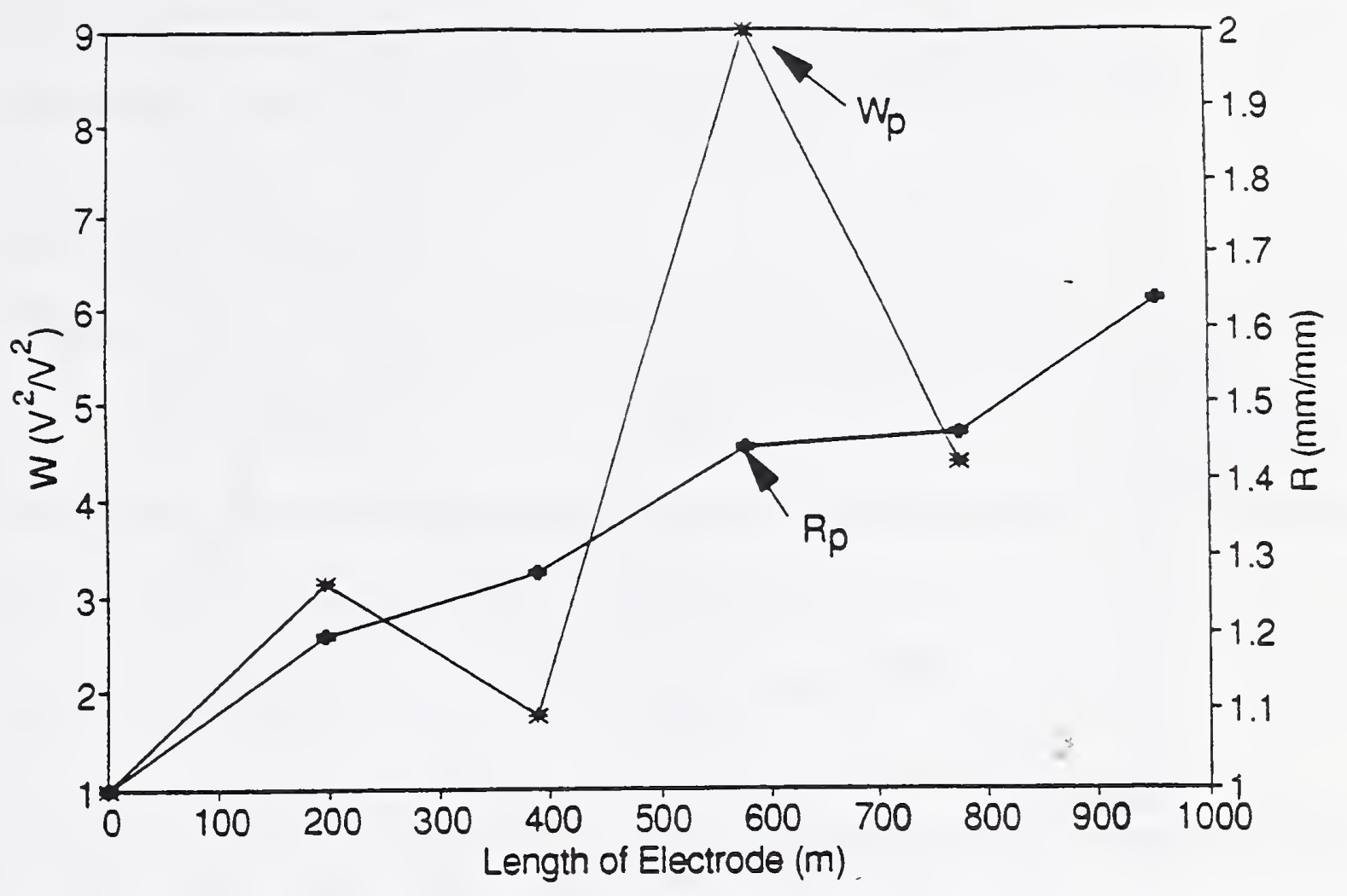

Figure 17. $W$ and $\mathbf{R}$ versus length of electrode fed for Tube A2.

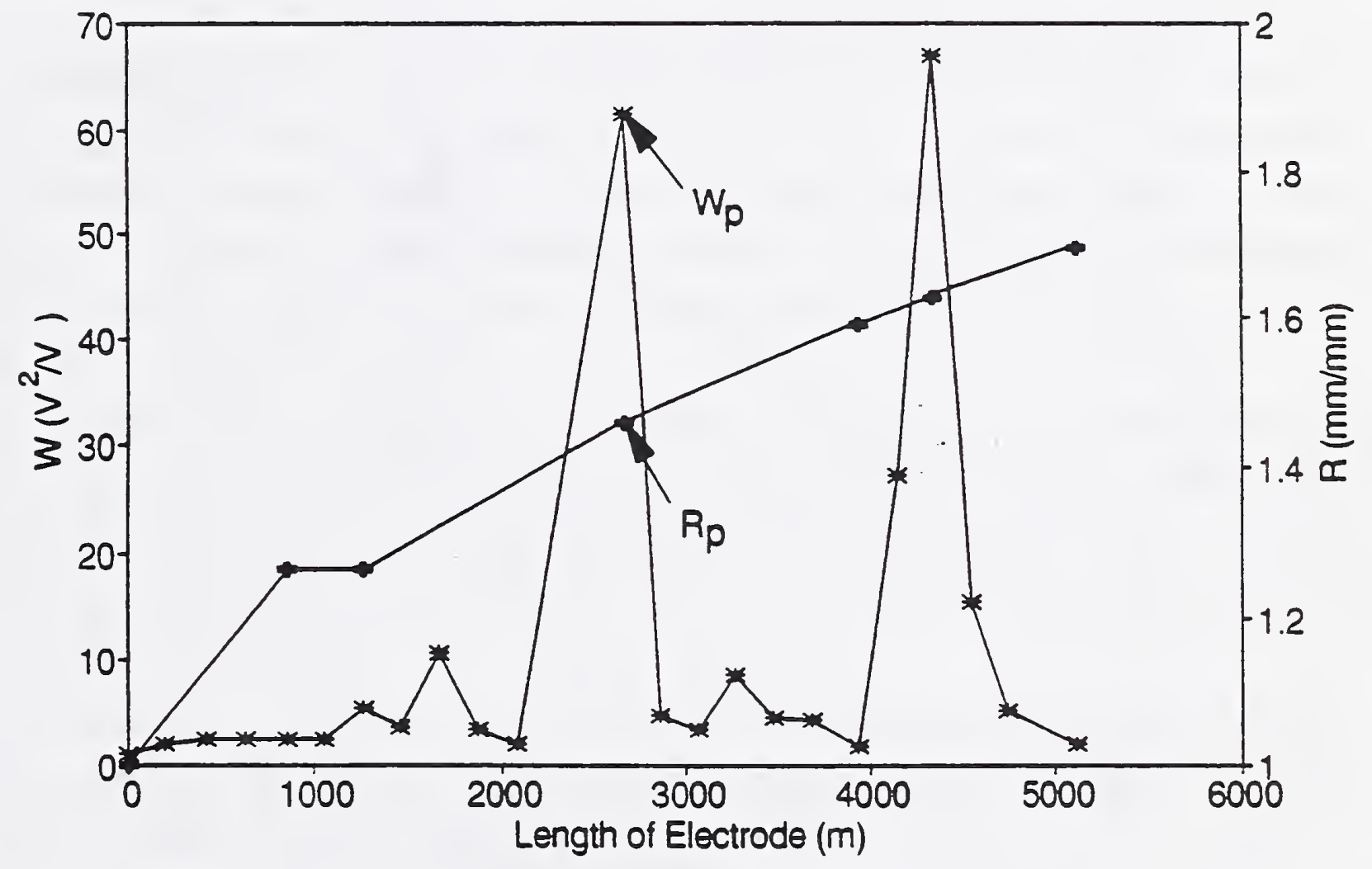

Figure 18. $W$ and $\mathbf{R}$ versus length of electrode fed for Tube B1. 


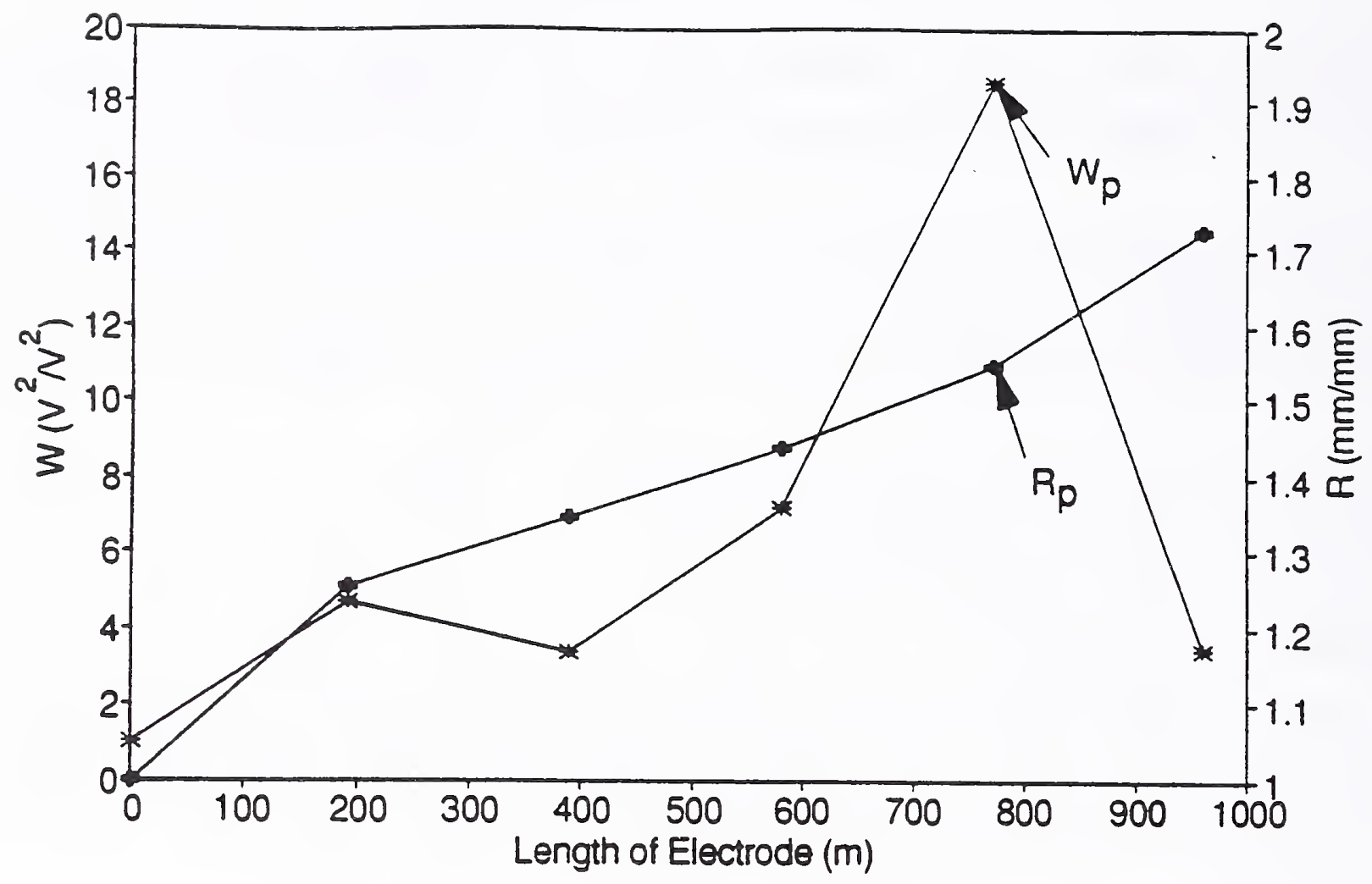

Figure 19. $W$ and $\mathbf{R}$ versus length of electrode fed for Tube $\mathrm{C} 1$..

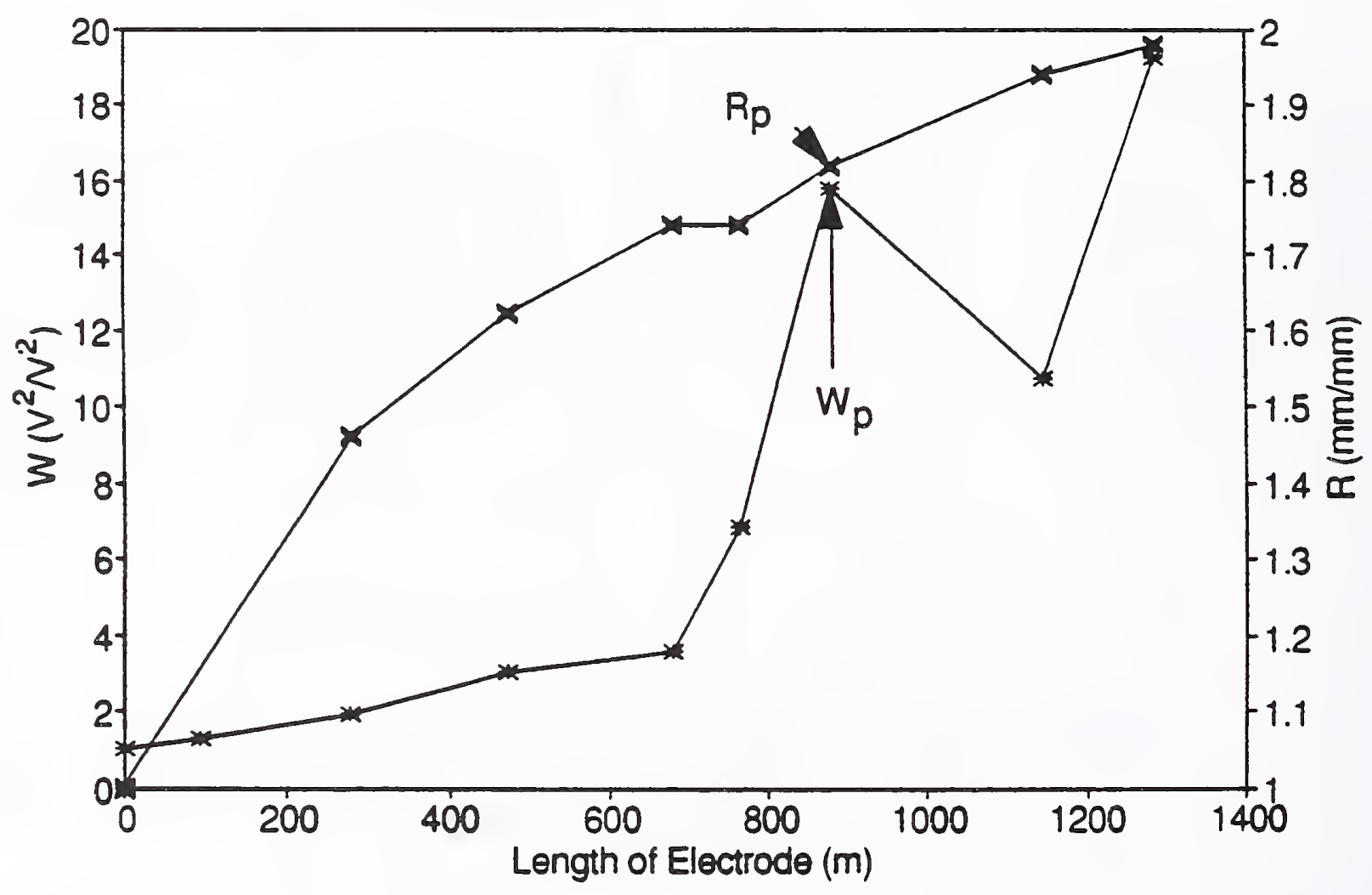

Figure 20. $W$ and $\mathbf{R}$ versus length of electrode fed for Tube S4. 
3.2.4 Sectioned Contact Tubes. Tubes A2, B1, C1, and S4 were cut longitudinally, on a plane perpendicular to the direction of wear. The areas of erosion and adhesion were detected and measurements taken with an image analyzer, see Table 4.

Table 4. Contact tube measurements.

\begin{tabular}{||l|l|l|l||}
\hline \hline $\begin{array}{l}\text { Tube } \\
\text { number }\end{array}$ & $\begin{array}{l}\text { Wear length } \\
(\mathrm{mm})\end{array}$ & $\begin{array}{l}\text { Adhesion length } \\
(\mathrm{mm})\end{array}$ & $\begin{array}{l}\text { Calculated } \\
\text { approach angle, } \\
\alpha \text { (degrees) }\end{array}$ \\
\hline \hline $\mathrm{A} 2$ & 15.32 & 1.754 & .0533 \\
\hline $\mathrm{B} 1$ & 16.07 & 1.564 & .0531 \\
\hline $\mathrm{C} 1$ & 12.89 & 1.910 & 0787 \\
\hline $\mathrm{S} 4$ & 14.10 & 8.540 & .0880 \\
\hline
\end{tabular}

Figure 21 shows the contact tube section which is perpendicular to the direction of wear, along with the wear and adhesion area, for tubes A2, B1, C1, and S4.

3.2.5 Discussion of Actual Wear Tests. To determine a relationship between $W_{\mathrm{p}}$ and $\mathbf{R}_{\mathrm{p}}$, the following were calculated; the change in tube exit contact length, contact surface area between the electrode and the contact tube during welding, and the volume of copper worn from the tube in relation to the angle of approach $(\alpha)$ and Dm. Figure 22 displays the geometric relationship between the electrode and the contact tube during welding. As the weld progresses, the electrode wears away the outlet of the contact tube in the direction of cast. The wear continues until the electrode has worn a notch, with the contour of the electrode, into the tube $\left(\beta=180^{\circ}\right)$.

Then, the contact that was originally a line at the exit between the electrode and the tube has reached a maximum, and the volume rate of wear decreases. The wear volume rate changes because the line contact reaches it maximum value, Figures 23,24 , and 25 . This occurrence closely corresponds to a value for $W_{p}$ (for $\mathrm{A} 2, \mathrm{~B} 1$, and $\mathrm{C} 1$ with a straight weld gun) at $R$ equal to $1.47 \mathrm{~mm} / \mathrm{mm}$.

As wear progresses, the point of current transfer can move within the electrode-tube contact surface, which is greater for a smaller approach angle $(\alpha)$. The voltage variance is produced by the changes in the voltage drop across the electrode extension and would continuously increase as the surface area of contact increases. Yamada and Tanaka determined that the point of current transfer is confined to the bottom one-fourth of the contact tube and that current passes to the electrode without sparking [3]. The voltage 


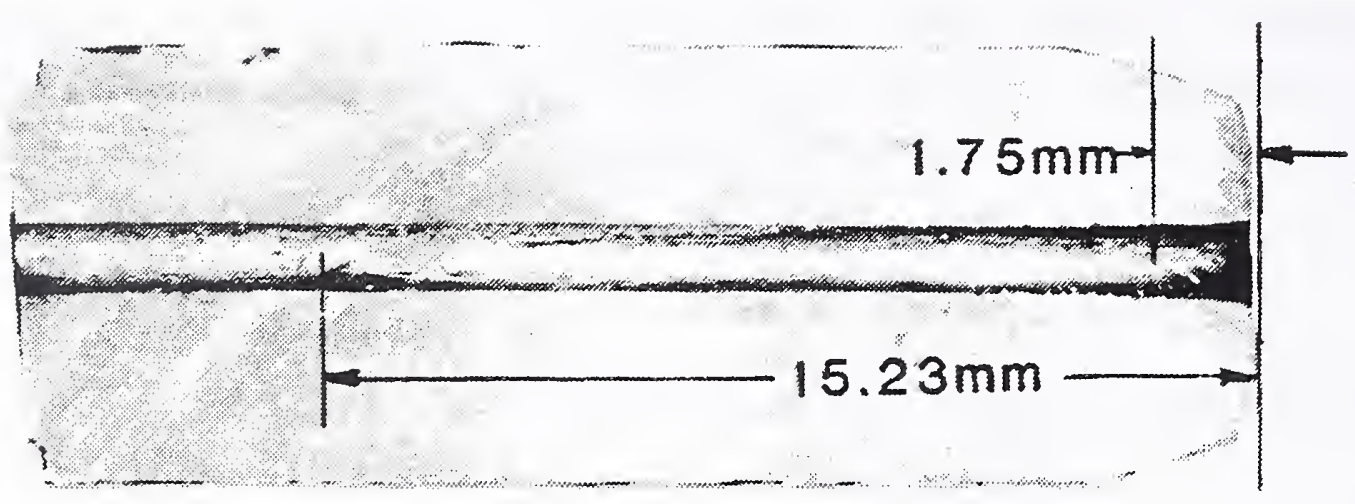

A2

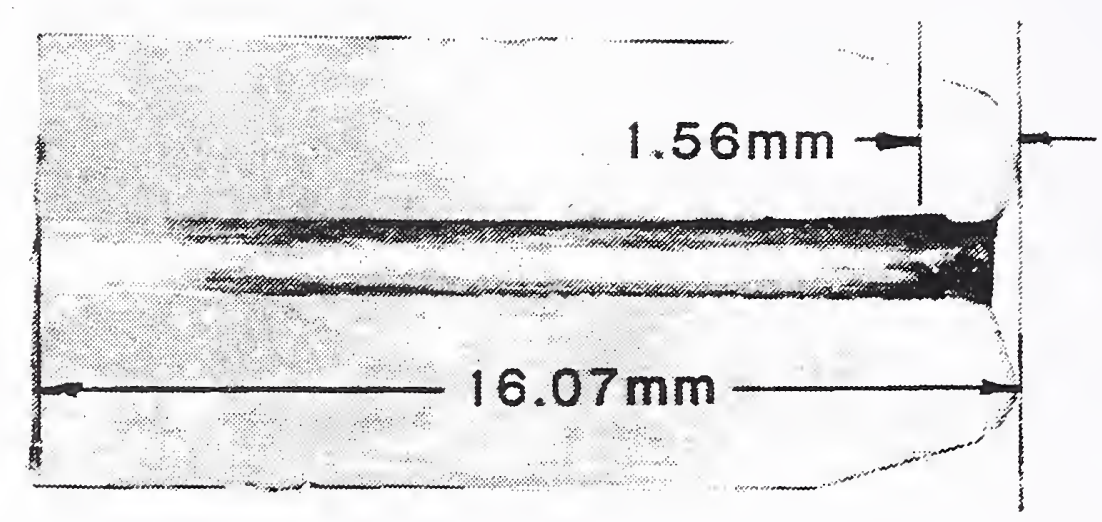

B 1
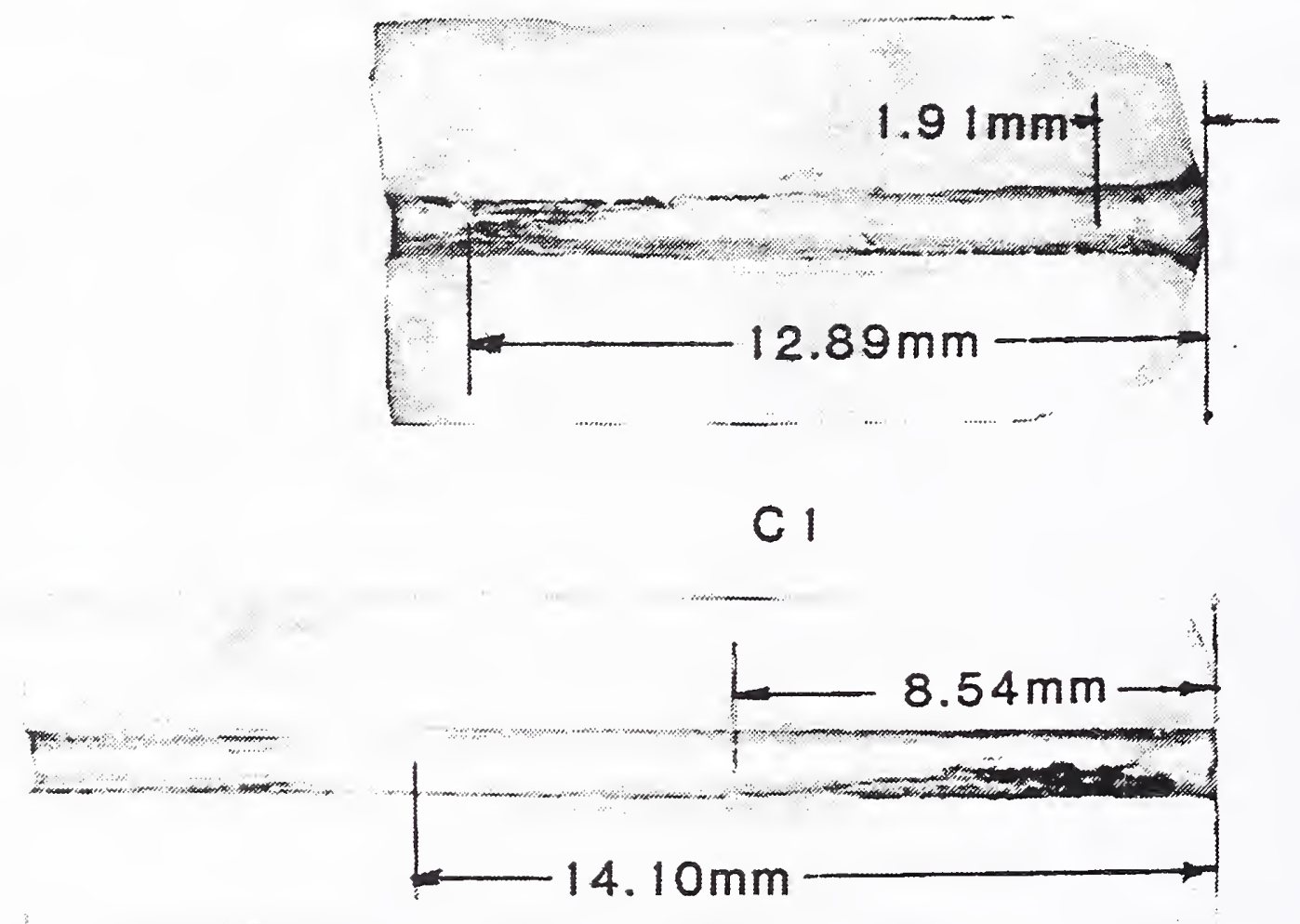

S4

Figure 21. Sectioned contact tubes. 

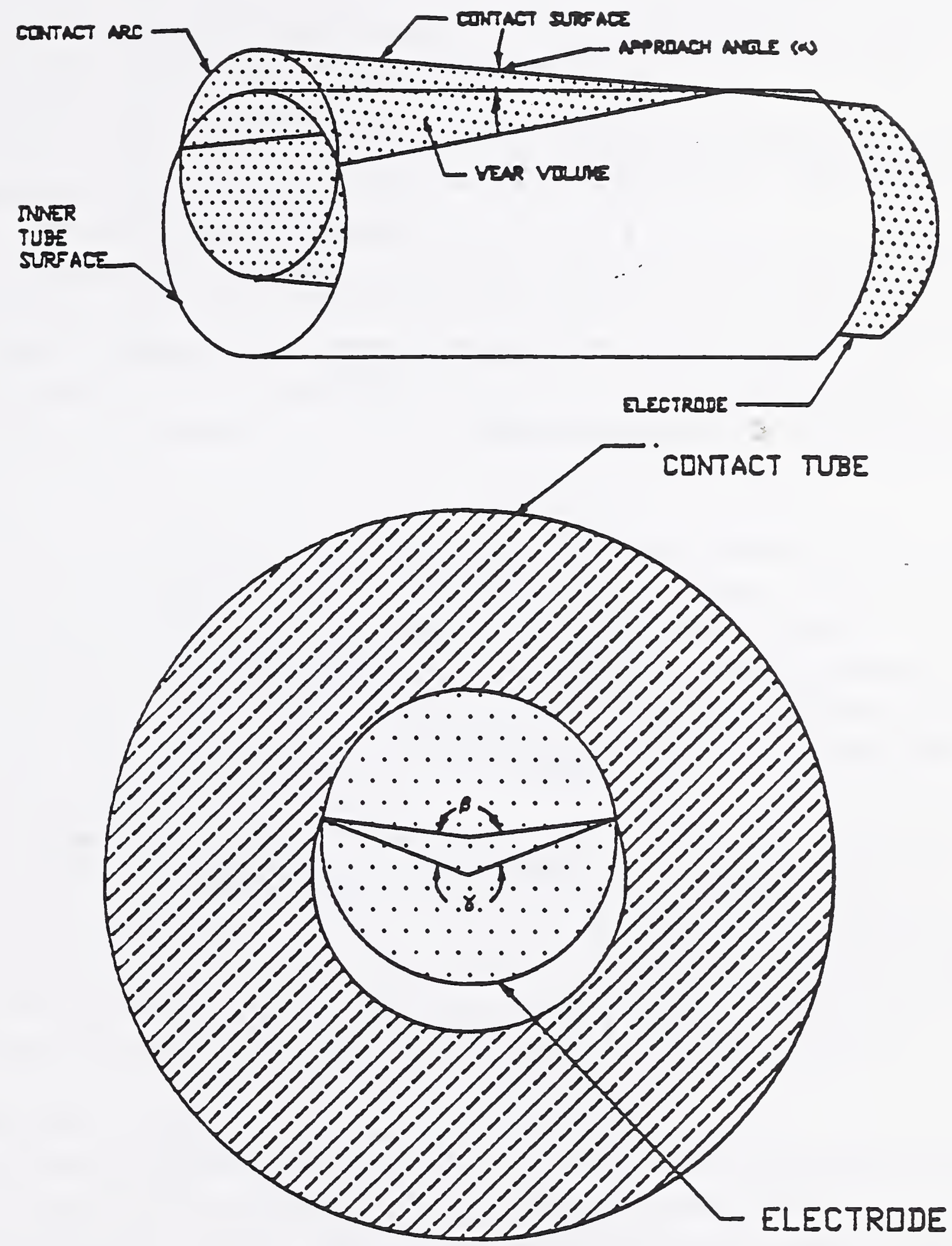

Figure 22. Electrode and tube wear configuration. 


\section{Configuration parameters versus $\mathbf{R}$}

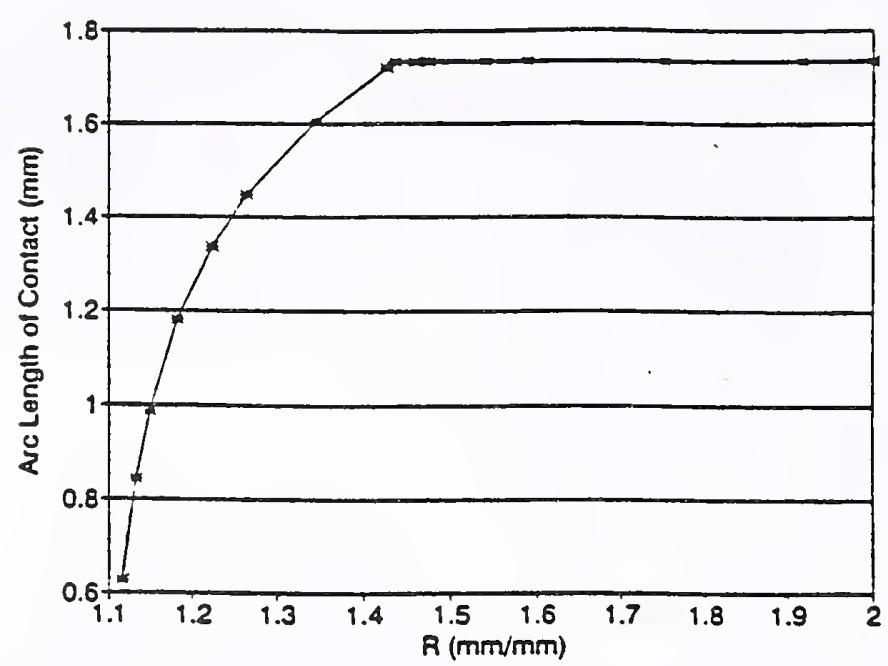

Figure 23. Arc length of contact versus $\mathbf{R}$.

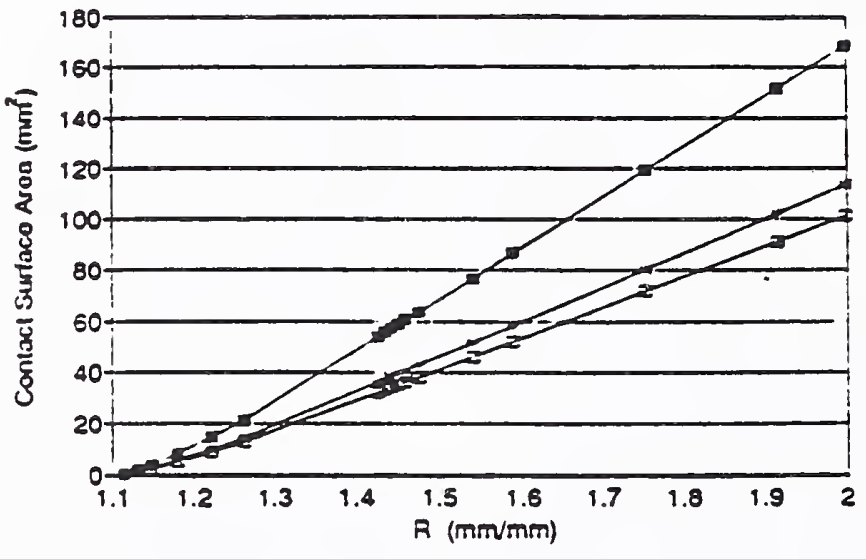

$\rightarrow$ Tube A2 $\longrightarrow$ Tube $\mathrm{B1}-$ Tubo $\mathrm{Cl} \longrightarrow$ Tube S4

Figure 24. Contact area versus $\mathbf{R}$.

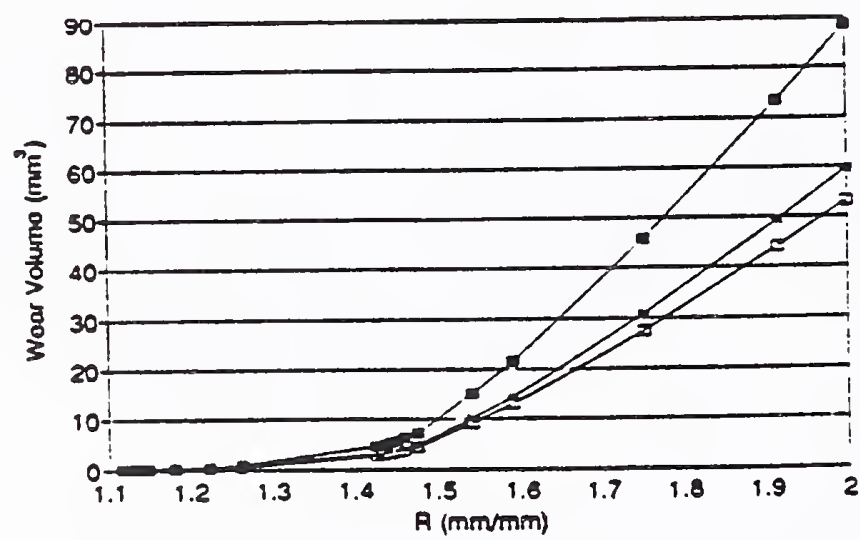

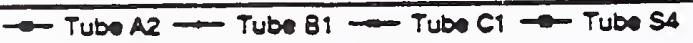

Figure 25. Wear volume versus $\mathbf{R}$. 
variance would be a function of surface contact area and is not necessarily a low-frequency process. If surface contact area were the only factor, tubes tested with the straight gun would have $W$ magnitudes greater than those for tubes with the curved gun, because the approach angle is less and the surface area of contact is greater for the depth of wear. The results of wear tests in this report do not indicate this.

The contact tube, S4, used in the curved gun has a larger ratio of adhesion area to surface contact area than the tubes used in a straight gun. Therefore, other factors, such as contact pressure, may affect the actual adhesion area.

The low-frequency voltage variance in a GMAW process with a pulsed-current power source and feedback control of the WFS, develops from a combination of variations in electrode extension and fluctuation in WFS due to adhesion. As mentioned earlier, adhesion (cold welding and hot welding) between the surfaces of the electrode and tube creates a junction which can be destroyed by the sliding motion of the electrode. Because the tube material is eroded with weld time for the steel electrode, separation occurs at the tube side of the junction.

When WFS is interrupted due to an adhesive bond, arc voltage increases, and in the weld power source used the electrode feed motor increases speed to compensate. As soon as the adhesive bond fails, the WFS is no longer restricted, but the controller has already recommended an increase in speed. The combined rise in speed lengthens the electrode extension and shortens the arc length. Then the controller signals the electrode feed motor to decrease speed. This cycle is affected by the control system, dynamics of the feeder motor, and frequency of adhesive bonds.

The maximum variance of the arc voltage $\left(W_{p}\right)$ at these low frequencies coincides with the point of maximum line contact at the exit of the tube and at the decrease in the rate of wear volume. If current transfer is limited to the extreme tip of the tube, the probability of adhesive bonds forming depends upon the line of physical contact between the electrode and the tube. The low-frequency changes in WFS are the consequence of increased frequency of adhesive contact between the electrode and the tube due to the enlarging line contact.

\subsection{Weave Test}

The welding test for tube S4 included testing with a $1 \mathrm{~Hz}$ weave imposed on the weld data. Test welds alternated between a linear weld progression (stringer bead) and an oscillating weld progression (weave bead). Figure 26 displays the PSD of voltage for a stringer bead collected immediately after replacing the contact tube (time 0 ) and the weave bead data collected thereafter ( $3 \mathrm{~min}$.).

Spikes at $1 \mathrm{~Hz}$ and at multiples of the weave frequency result from the voltage variation caused by the weaving (Figure 27). 


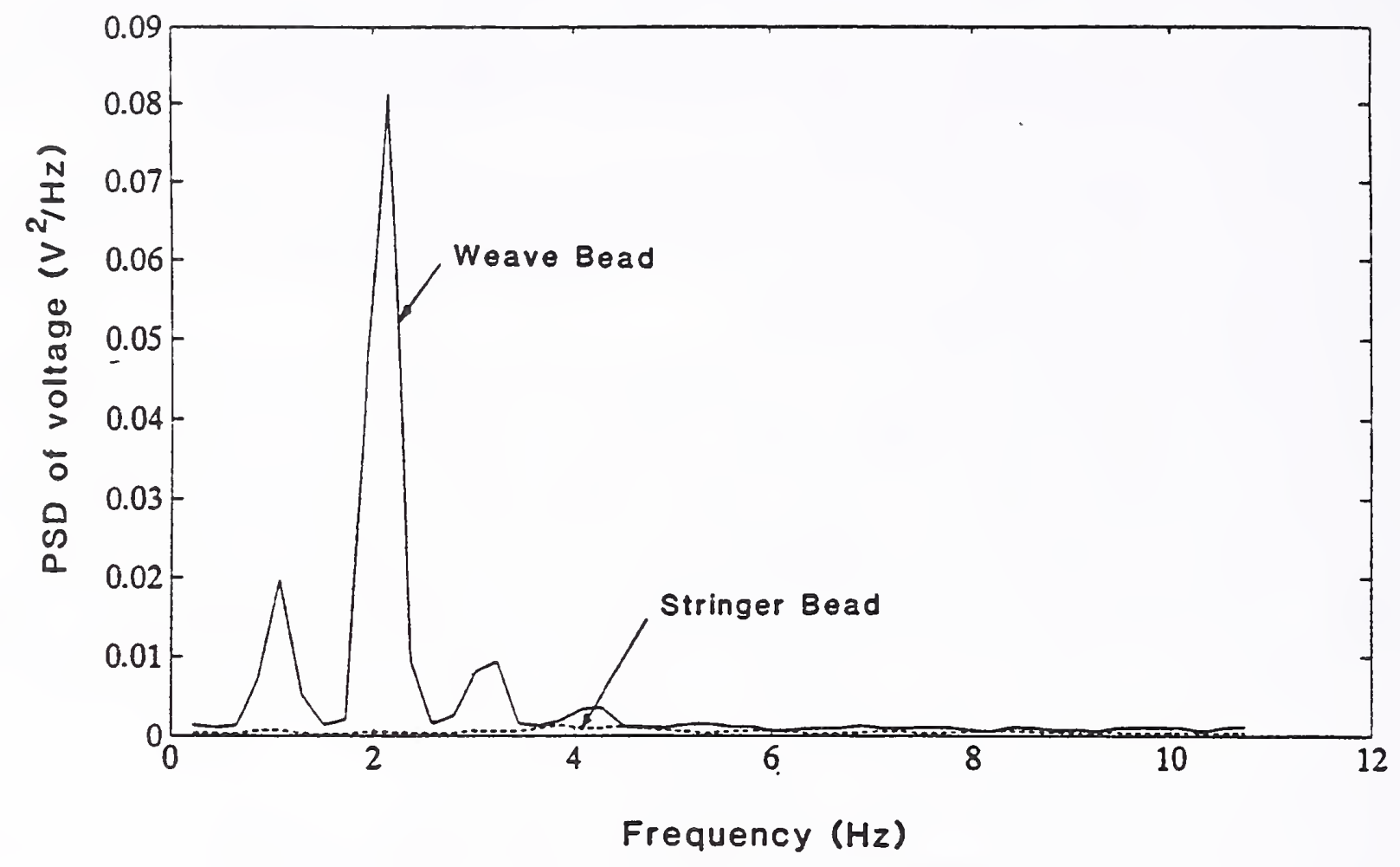

Figure 26. PSD voltage for sequential stringer and $1 \mathrm{~Hz}$ weave beads with a new contact tube.

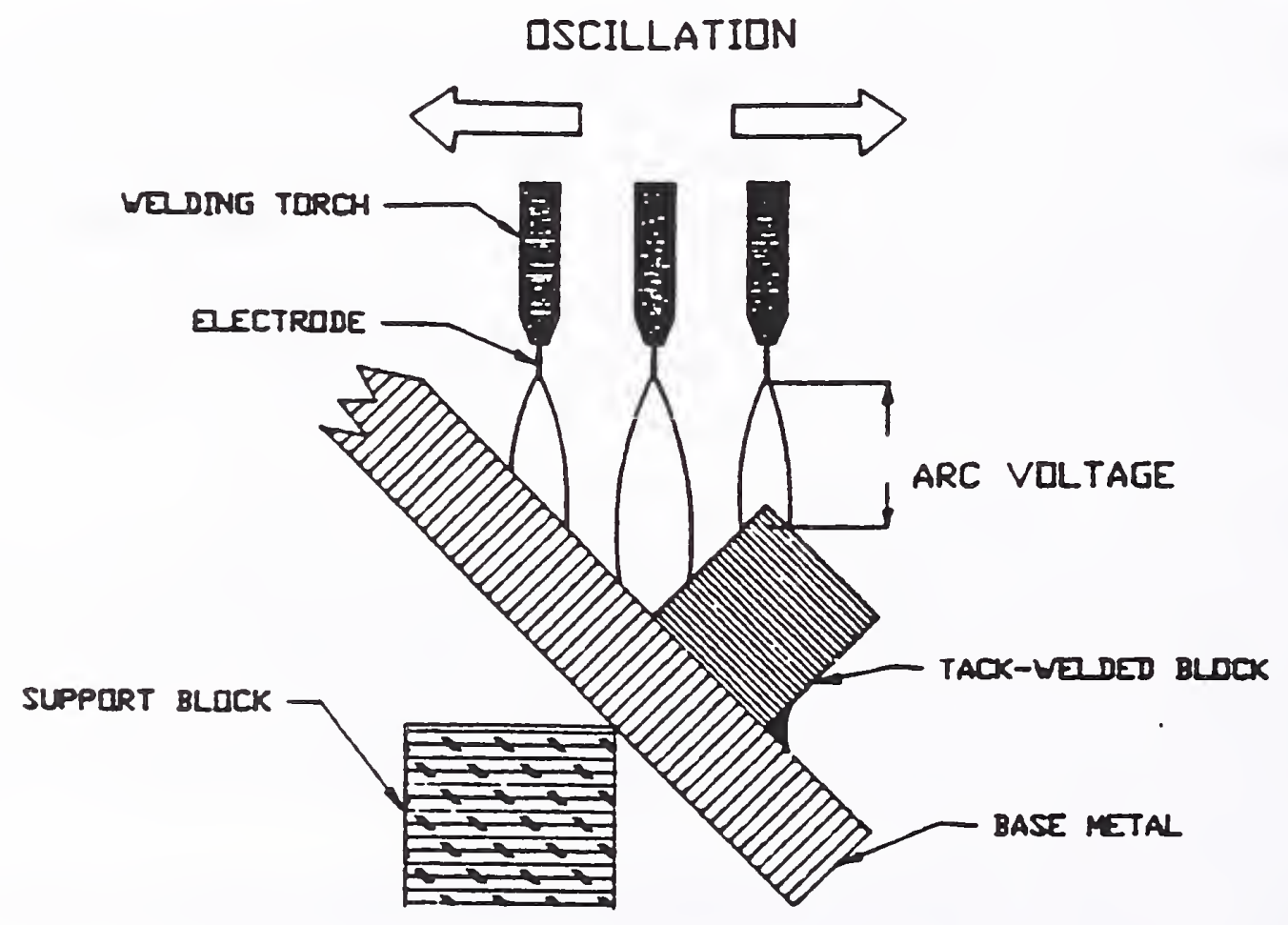

Figure 27. Weave geometry. 
Figure 28 shows $W$ for the stringer test weld and the $1 \mathrm{~Hz}$ weave test weld. The value of $W$ for a weave bead can presently be used as a wear monitor only if welding conditions are kept constant. Welding a weave bead along a skewed path or filling a groove with multiple passes, creates variations in the frequency and magnitude of the weave voltage data [10].

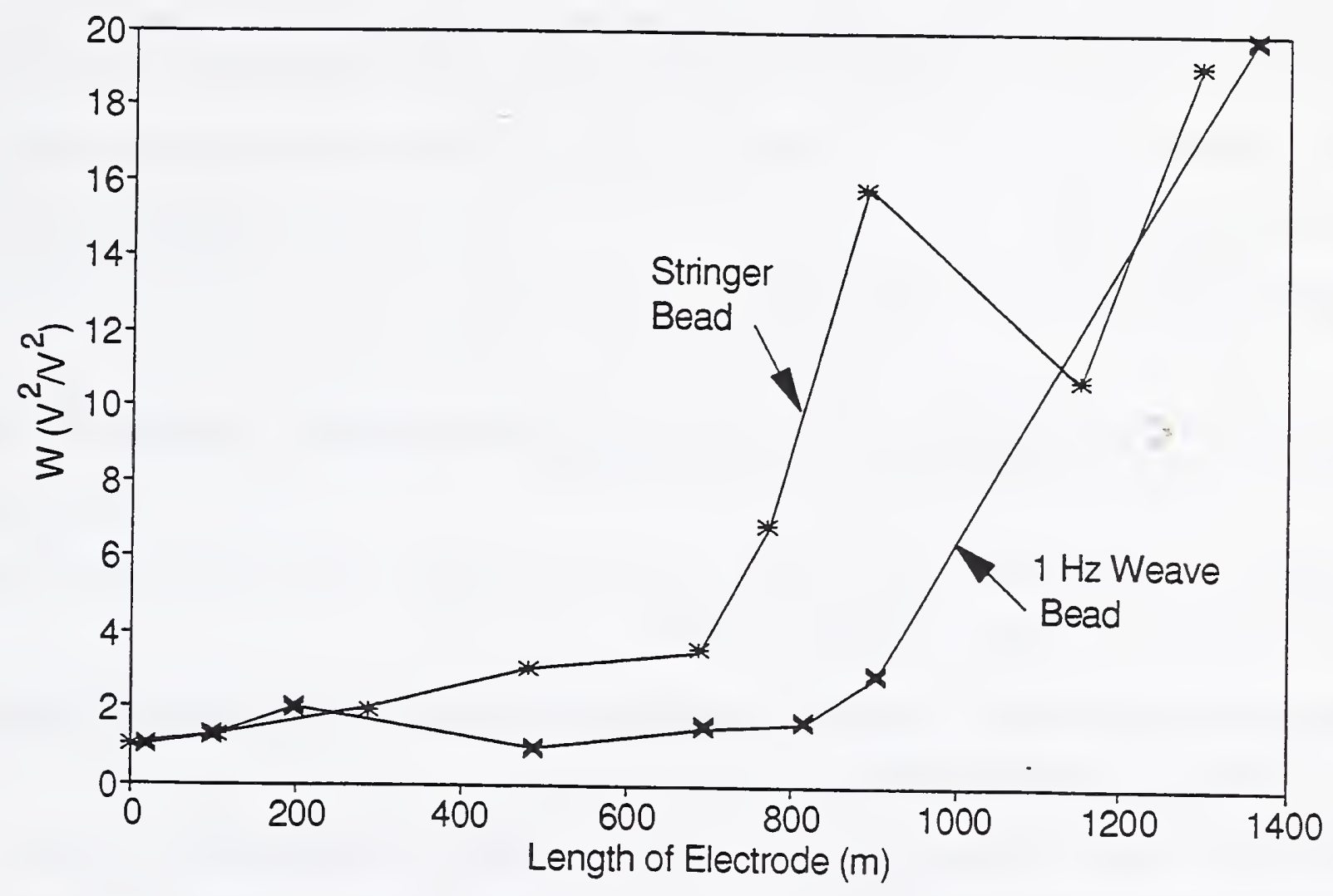

Figure 28. $W$ versus length of electrode for stringer and weave tests.

\section{CONCLUSIONS}

1. Through-the-arc sensing can detect contact tube wear for the conditions of these tests. These experiments show that the variance of the welding voltage correlates to contact tube wear.

2. The area, $W$, under the power spectral density curve from 0 to $4 \mathrm{~Hz}$ identifies a point in welding when the voltage variance has reached a maximum, and the electrode has worn a slot with the maximum length of contact in the contact tube. This point can be used to indicate the time to replace the tube.

3. The simulated-wear tests suggest that a contact-tube-to-electrode-bore ratio of less than 1.6 would provide a droplet-transfer mode with low standard deviation of droplet frequency, thus providing consistent weld characteristics. 
Financial and technical support from the U.S. Navy Programmable Automated Welding System (PAWS) program, Charles Null, NAVSEA 5142, Program Manager, and R.A. Morris, Naval Surface Weapons Center, Technical Manager, is acknowledged. R.B. Madigan, of NIST, provided expertise in welding and instrumentation. S. Liu, of the Colorado School of Mines, provided insight into the effects of electrode weave and arranged the use of some equipment.

\section{REFERENCES}

1. American Welding Society (AWS). 1991. Welding Handbook; Welding Processes. Ed. R. L. O'Brien. 8th ed. Vol 2. Miami, Florida.

2. DeNale, R. and Lukens, W.E. 1986. Increasing Contact Tube Life During Titanium Gas Metal Arc Welding. Welding Journal. 65(1):28-33.

3. Yamada, T. and Tanaka, O. 1987. Fluctuation of the Wire Feed Rate in Gas Metal Arc Welding. Welding Journal. 66(9):35-42.

4. Schey, J.A. 1983. Tribology in Metal Working; Friction, Lubrication and Wear. ASM International. Metals Park, Ohio.

5. Brandis, E.A. 1983. Smithells Metals Reference Book. Butterworths, London.

6. Copper and Copper Alloys. 1989. Volume 02.01 of Annual Book of ASTM Standards. American Society for Testing and Materials, Philadelphia.

7. Heald, P.R., Madigan, R.B., Siewert, T.A., and Liu, S., 1991. Droplet Transfer Modes for a MIL 100S-1 GMAW Electrode. NISTIR 3976. National Institute for Standards and Technology. Gaithersburg, Maryland.

8. Eagar, T.W., Allemand, C.D., Schoeder, R., and Ries, D.E. 1985. A Method for Filming Metal Transfer in Welding Arcs. Welding Journal. 64(1):45 to 47

9. Bendat \& Piersol, 1971. Random Data: Analysis and Measurement Procedures. Wiley-Interscience. New York, N.Y.

10. Cook, G., Randall, M., Shepard, M., Yizhang, L. 1986. Adaptive Submerged Arc Welding Control. International Conference on Trends in Welding Research, S.A.

David, ed. ASM International. Metals Park, Ohio. 


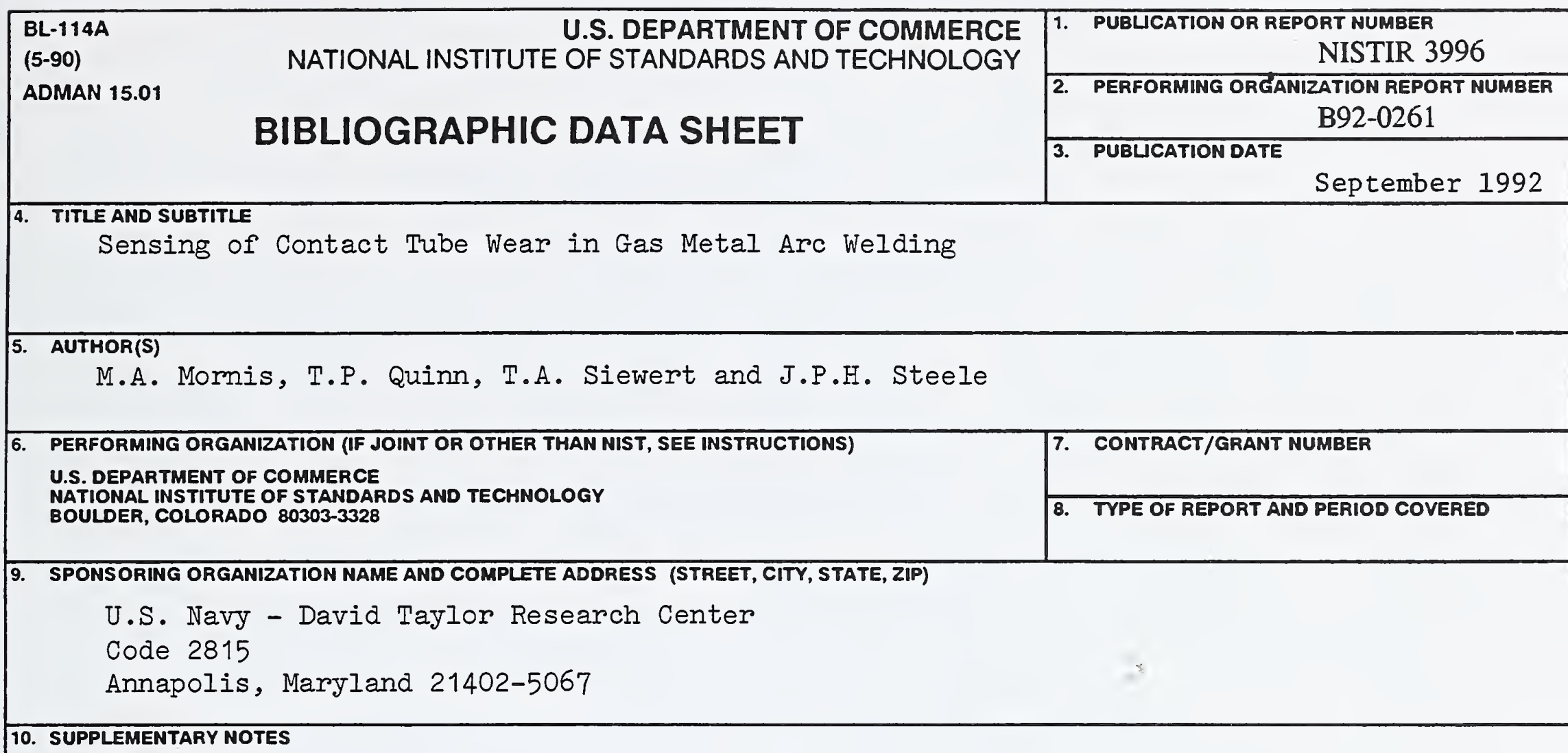

11. ABSTRACT (A 200-WORD OR LESS FACTUAL SUMMARY OF MOST SIGNIFICANT INFORMATION. IF DOCUMENT INCLUDES A SIGNIFICANT BIBLIOGRAPHY OR LTERATURE SURVEY, MENTION IT HERE.)

Welding tests confirmed that the circuit voltage can serve as a through-the-arc sensing parameter for monitoring contact tube wear in gas metal arc welding. The integral power spectral density curve $(W)$ of the voltage, within the 0 to $4 \mathrm{~Hz}$ range, correlated with wear. $W$ in this frequency range was found to measure the arc stability, which degraded as the contact tube was eroded by the electrode. $W$ reached a peak value when the wear reached the maximum line contact between the electrode and the contact tube, then the $W$ became erratic as the electrode started to oscillate within the slot that had worn in the tube.

12. KEY WORDS (6 TO 12 ENTRIES; ALPHABETICAL ORDER; CAPITALIZE ONLY PROPER NAMES; AND SEPARATE KEY WORDS BY SEMICOLONS) contact tube wear; current; gas metal arc welding; sensing; through-the-arc sensing; voltage; weld sensing

14. NUMBER OF PRINTED PAGES

$$
39 .
$$

15. PRICE

$\mathrm{AO} 3$ 



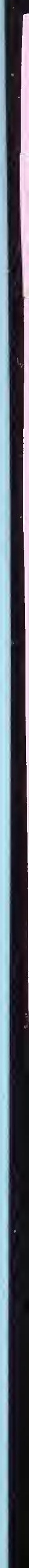

